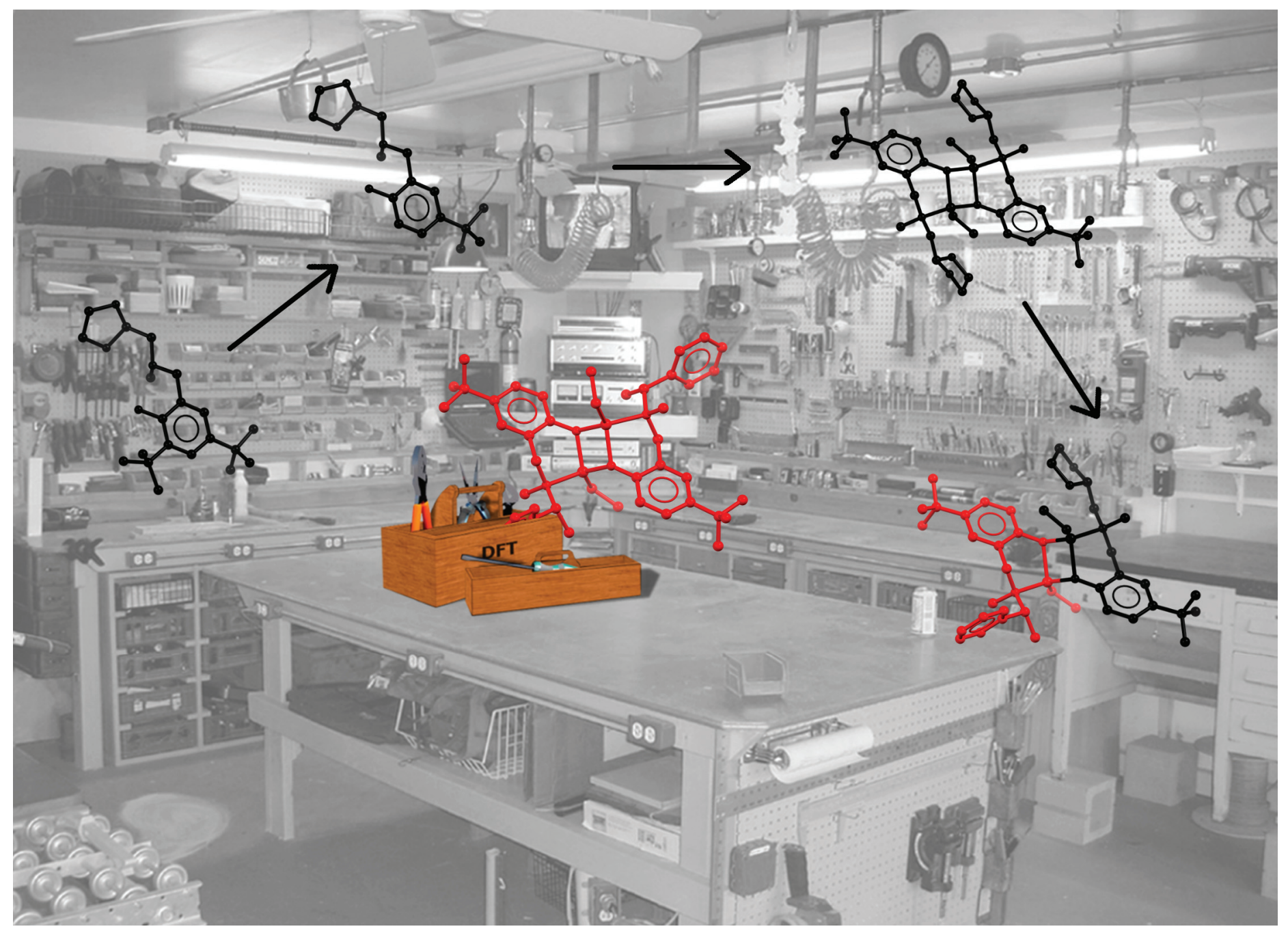

Showcasing latest work of Jolanta Ejfler et al. from University of Wroctaw, Poland.

DFT calculations as a ligand toolbox for the synthesis of active initiators for ROP of cyclic esters

The presented examples herein of new zinc complexes indicate that theoretical DFT calculations can be a valuable synthetic toolbox to tailor interesting new complexes for coordination chemistry and catalysis.

\section{As featured in:}

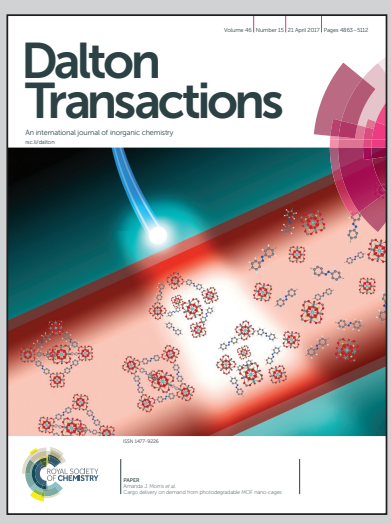

See J. Ejfler et al., Dalton Trans., 2017, 46, 4929.

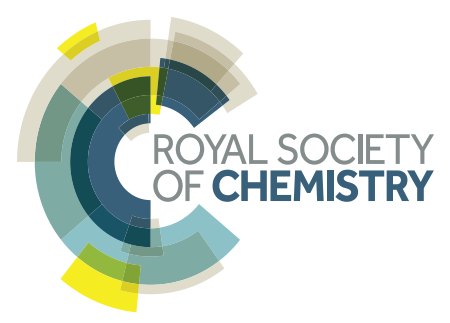




\section{(A) Check for updates}

Cite this: Dalton Trans., 2017, 46 4929

Received 1st February 2017, Accepted 6th March 2017

DOI: $10.1039 / c 7 d t 00394 c$ rsc.li/dalton

\title{
DFT calculations as a ligand toolbox for the synthesis of active initiators for ROP of cyclic esters $\uparrow$
}

\author{
D. Jędrzkiewicz, D. Kantorska, J. Wojtaszak, J. Ejfler (D)* and S. Szafert
}

\begin{abstract}
New heteroleptic zinc dimeric complexes bearing an aminophenolate ligand of a single-site initiator framework were synthesized and characterized by spectroscopic methods, X-ray analysis, and DFT calculations. The theoretical study, verified by the experimental data, explains the catalytic behaviour in the ROP of lactide in the examined zinc complexes. The presented simple DFT protocol constitutes a valuable method for the qualification of the ancillary ligand to rationally design new complexes to improve their catalytic activity.
\end{abstract}

\section{Introduction}

Recently, the synthesis of polymers with programmable by design properties - those suitable for various applications have attracted significant attention. The most attractive polymers are those dedicated to nanomedicine, molecular engineering and bio-base active packages. ${ }^{1-5}$ Polylactide (PLA) is one of the advanced green polymers, recently commercialized in worldwide production, that has tremendous application potential in the fields of bio-interface materials for surgery, regenerative medicine, tissue engineering, pharmacy, biodegradable packaging and environmentally friendly polymers. ${ }^{6-10}$

The ring opening polymerization (ROP) of cyclic esters initiated by metal complexes is the most effective procurement method of PLA among the numerous synthetic procedures studied to date. The heteroleptic metal complexes of the general formula $\mathrm{L}-\mathrm{M}-\mathrm{OR}$ (where, L-ancillary ligand, M-metal centre, and OR-initiating group) are regarded as the best option to access PLA in a controlled and stereo-selective manner. Therefore, the synthesis of well-defined, single-site initiators based on these structural motifs has been the subject of intensively developed studies over the past decade. ${ }^{11-15}$ Excellent initiators have been obtained that were supported by di-, tri-

Faculty of Chemistry, University of Wroclaw, 14 F. Joliot-Curie, 50-383 Wroclaw, Poland.E-mail: jolanta.ejfler@chem.uni.wroc.pl

$\dagger$ Electronic supplementary information (ESI) available: X-ray crystallographic CIF files for $\left(\mathbf{L}^{\mathbf{o x}} \mathbf{Z n E t}\right)_{2}, \mathbf{L}^{{ }^{R}} \mathbf{L}^{\mathrm{cy}} \mathbf{Z n}_{2} \mathbf{E t}_{2}$; spectroscopic data for $\mathbf{L}^{\mathrm{ox}}-\mathbf{H},\left(\mathbf{L}^{\mathrm{ox}} \mathbf{Z n E t}\right)_{2}$, $\mathbf{L}^{R} \mathbf{L}^{\mathbf{o x}} \mathbf{Z n}_{2} \mathbf{E t}_{2}$; computational data: schematic and gas-phase optimized structures of zinc isomers; energies of structures optimized in vacuo; selected bond distances and angles for DFT optimized structures. CCDC 1511741 and 1511742. For ESI and crystallographic data in CIF or other electronic format see DOI: $10.1039 / \mathrm{c} 7 \mathrm{dt} 00394 \mathrm{c}$ and recently tetra-valent metal centres and coordinated by numerously ancillary ligand families. ${ }^{16-19}$ In the context of biomedical applications and environmentally friendly technologies, the complexes that contain biometals ( $\mathrm{Ca}, \mathrm{Mg}$, and $\mathrm{Zn}$ ) are still the most searched. However, the kinetic instability of these heteroleptic compounds requires precision in matching appropriate ancillary ligands with a metal centre to prevent a deactivation pathway or ligand redistribution reaction. Excellent initiators have been obtained using biometals coordinated by numerous ancillary ligands such as $\beta$-diketiminate, ${ }^{20-24}$ tris(pirazolyl)borate, ${ }^{25-29}$ and related N,O-donor ligands. ${ }^{29-45}$ However, most of them have been generated by in situ alcoholysis of alkyl LMR/(LMR $)_{2}$ compounds.

In contrast, over the last few years, aminophenol ligands have been used in the construction of new single-site initiators. As a result of the prevailing trend, extensive attention was paid to this type of ancillary ligand, which caused the appearance of a significant and still growing database of alkyl aminophenolate metal complexes. However, for previously studied ligands, the set of well-defined aminophenolate complexes with single-site motifs is very limited. The single-site type zinc complexes with aminophenol ligands are known, but it is worth remembering that although the motif $(\mathrm{LZnOR})_{2}$ seems simple, its synthesis is elaborate, which has been supported by only four documented (X-ray) compounds to date (Scheme 1). Another alternative, the binary catalytic systems based on the $\mathrm{L}_{2} \mathrm{M} / \mathrm{ROH}$ combination, are also worth noticing because some of them might have the tendency to indicate selectivity towards polymerization or alcoholysis of lactides. ${ }^{41,42}$ Particularly, this feature is of interest in view of the growing need for PLA and other valuable materials, such as lactyl-lactate/lactate esters, which have applications in cosmetics, fragrances and food additives. 


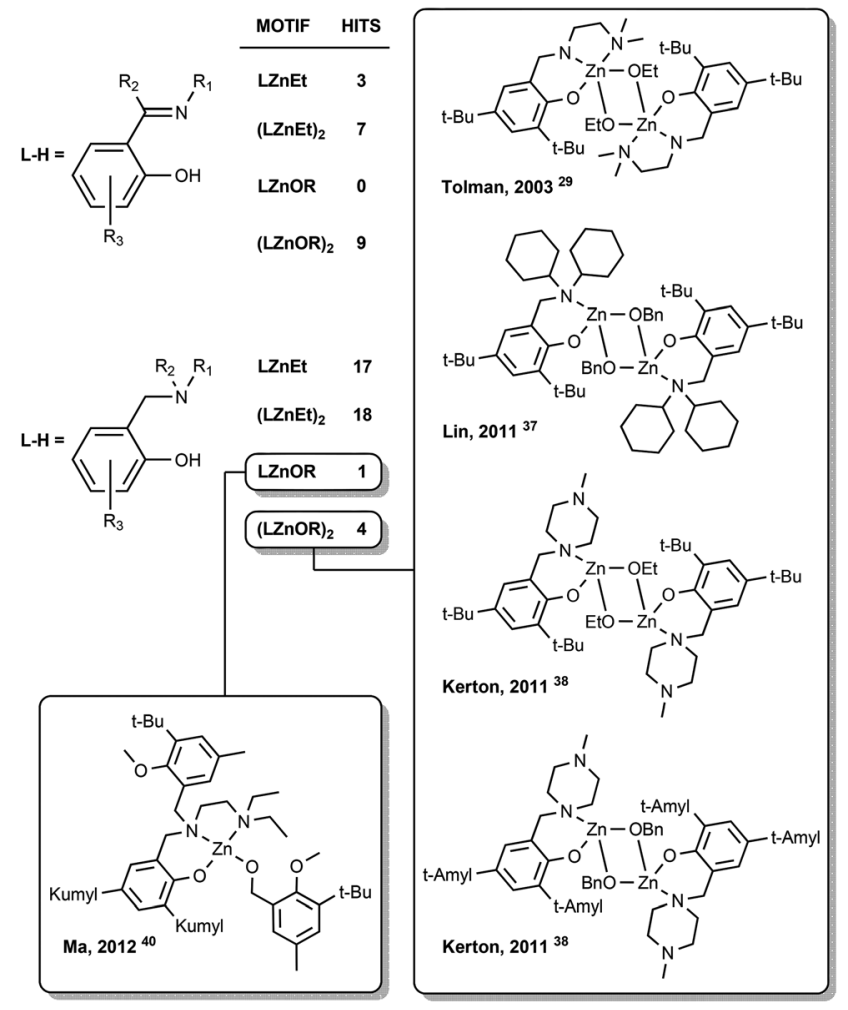

Scheme 1 Examples of well-defined (CCDC data base) imino/aminophenolate zinc complexes. ${ }^{29,37,38,40}$

The synthesis of both (LZnEt) $)_{2}$ and $\mathbf{L}_{2} \mathbf{Z n}$ compounds is strongly connected with the coordination properties of aminophenolate ligands, and one of the most important factors is mutual interaction of substituents introduced to the amine arm and aryl core. Recently, we have explored the combination of functionalized aminophenol ligands with $\mathrm{ZnEt}_{2}$ for targeted hetero/homoleptic (LZnEt) $)_{2}$ complexes synthesis (Scheme 2) ${ }^{43,44}$ Our study extensively correlated the experimental outcomes with DFT calculations in rationalization of ancillary ligand design for zinc complexes with a programmable structural motif. Likewise, for these complexes, the modulation of the substituents located on the phenyl and amine arm permit the matching of the precise synthetic protocol for exactly one type of complex formation: hetero/homoleptic dimers or homoleptic monomers. Herein, we described the design of ancillary ligands for zinc complexes with the view of predicting their catalytic activity in the ROP of lactides using DFT calculations as a synthesis rating before its experimental verification.

\section{Experimental}

\section{Materials and methods}

All reactions and operations were performed under an inert atmosphere of $\mathrm{N}_{2}$ while using a glove-box (MBraun) or standard Schlenk apparatus and vacuum line techniques. The sol-
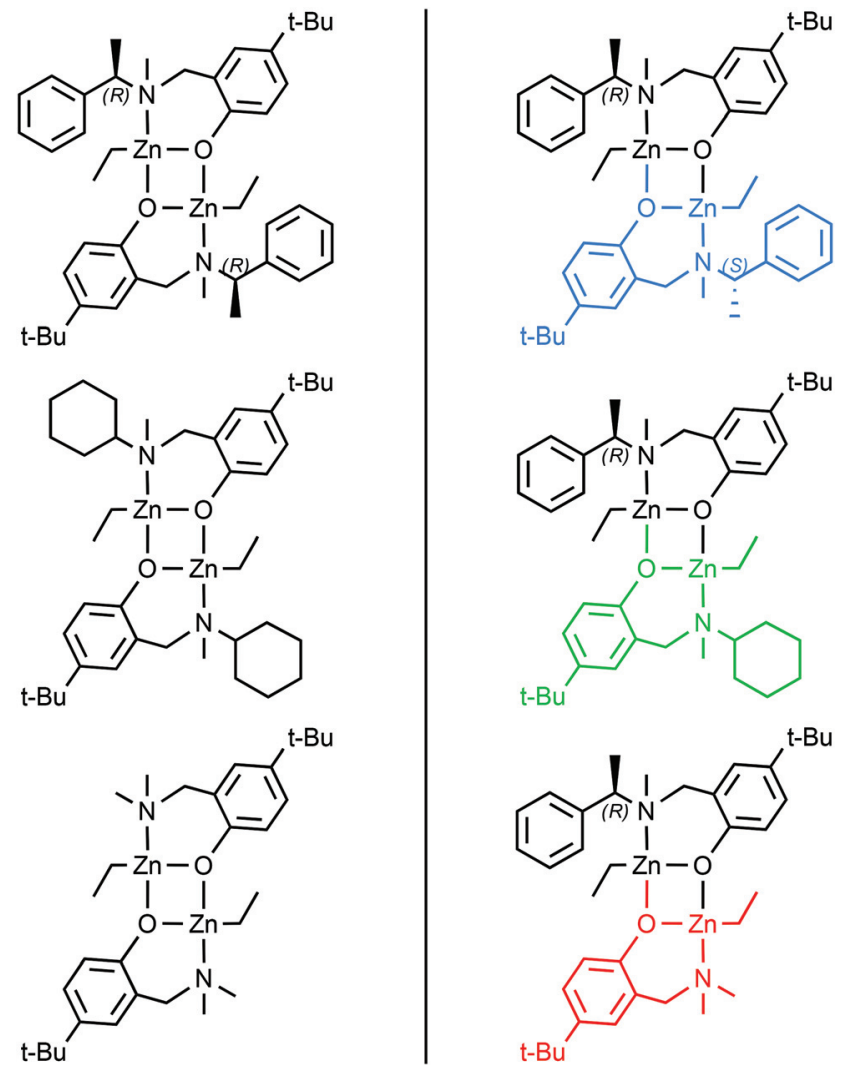

Scheme 2 Examples of ethyl zinc homo (left) and hetero (right) dimers.

vents were purified by standard methods: methanol, distilled from $\mathrm{Mg}$; toluene, distilled from $\mathrm{Na} ; \mathrm{CH}_{2} \mathrm{Cl}_{2}$, distilled from $\mathrm{P}_{2} \mathrm{O}_{5}$; hexanes, distilled from $\mathrm{Na} ; \mathrm{C}_{6} \mathrm{D}_{6}$, distilled from $\mathrm{CaH}_{2}$. L-LA ((3S)-cis-3,6-dimethyl-1,4-dioxane-2,5-dione) (98\%; Aldrich) was sublimed and recrystallized from toluene prior to use. Benzyl alcohol (Aldrich) was distilled under dry nitrogen gas and freeze/thaw degassed prior to use. $\mathrm{ZnEt}_{2}(1.0 \mathrm{M}$ solution in hexanes), 4-tert-butylphenol, 2-methylaminomethyl-1,3dioxolane $(98 \%)$, and formaldehyde ( $37 \%$ solution in $\mathrm{H}_{2} \mathrm{O}$ ) were purchased from Aldrich and used as received. $\left(\mathbf{L}^{R} \mathbf{Z n E t}\right)_{2}$ was obtained according to the literature method. ${ }^{44}{ }^{1} \mathrm{H}$ and ${ }^{13} \mathrm{C}$ NMR spectra were detected over a temperature range from 233 to $333 \mathrm{~K}$ using Bruker ESP $300 \mathrm{E}$ or $500 \mathrm{MHz}$ spectrometers. Chemical shifts are reported in parts per million and referenced to residual protons in deuterated solvents. Microanalyses were conducted with an ARL Model 3410 + ICP spectrometer (Fisons Instruments) and a VarioEL III CHNS (in-house).

\section{Syntheses}

$N$-[Methyl(2-hydroxy-5-tert-butylphenyl)]- $N$-methyl- $N$-methyl1,3-dioxolaneamine $\left(\mathrm{L}^{\mathrm{ox}}-\mathrm{H}\right)$. To a stirred solution of $1.32 \mathrm{~g}$ (8.78 mmol) of 4-tert-butylphenol and $1.00 \mathrm{~mL}(8.78 \mathrm{mmol})$ of 2-methylaminomethyl-1,3-dioxolane in $\mathrm{MeOH}(50.00 \mathrm{~mL})$, $0.90 \mathrm{~mL}(11.97 \mathrm{mmol})$ of formaldehyde $\left(37 \%\right.$ solution in $\left.\mathrm{H}_{2} \mathrm{O}\right)$ was added at ambient temperature. The mixture was stirred, 
and the clear solution was heated under reflux for $24 \mathrm{~h}$. The crude product was obtained as a colourless oil after evaporation of the solvent in vacuo. Next, the oil product was dissolved in hexanes, and after addition of cold $\mathrm{MeOH}$, a white solid precipitated. It was collected by filtration, washed with cold $\mathrm{MeOH}$ and dried in vacuo to give $\mathbf{L}^{\mathbf{0 x}}-\mathbf{H}$ in $89 \%$ yield (2.18 g, $7.81 \mathrm{mmol}$ ). Anal. Calcd (Found) for $\mathrm{C}_{16} \mathrm{H}_{25} \mathrm{NO}_{3}$ (\%): C, 68.79 (68.68); H, 9.02 (9.24); N, 5.01 (5.07); ESI/MS: 279.2 $[\mathrm{M}+1]^{+} ;{ }^{1} \mathrm{H}$ NMR $\left(500 \mathrm{MHz}, \mathrm{CDCl}_{3}, \mathrm{RT}\right): \delta=7.17\left(\mathrm{dd}, J_{\mathrm{HH}}=\right.$ 8.4, $2.5 \mathrm{~Hz}, \operatorname{ArH}, 1 \mathrm{H}), 6.95\left(\mathrm{~d}, J_{\mathrm{HH}}=2.4 \mathrm{~Hz}, \operatorname{ArH}, 1 \mathrm{H}\right), 6.76(\mathrm{~d}$, $\left.J_{\mathrm{HH}}=8.4 \mathrm{~Hz}, \mathrm{ArH}, 1 \mathrm{H}\right), 5.05\left(\mathrm{t}, J_{\mathrm{HH}}=4.1 \mathrm{~Hz}, \mathrm{O}_{2} \mathrm{CH}-\mathrm{CH}_{2}-\mathrm{N}\right.$, $1 \mathrm{H})$, 4.06-3.81 (m, O- $\left.\mathrm{CH}_{2}-\mathrm{CH}_{2}-\mathrm{O}, 4 \mathrm{H}\right), 3.78\left(\mathrm{~s}, \mathrm{Ar}-\mathrm{CH}_{2}-\mathrm{N}\right.$, $2 \mathrm{H}), 2.73\left(\mathrm{~d}, J_{\mathrm{HH}}=4.1 \mathrm{~Hz}, \mathrm{O}_{2} \mathrm{CH}-\mathrm{CH}_{2}-\mathrm{N}, 2 \mathrm{H}\right), 2.38\left(\mathrm{~s}, \mathrm{~N}-\mathrm{CH}_{3}\right.$, $3 \mathrm{H}), 1.27\left(\mathrm{~s}, \mathrm{C}\left(\mathrm{CH}_{3}\right)_{3}, 9 \mathrm{H}\right) ;{ }^{13} \mathrm{C}\left\{\mathrm{H}^{1}\right\} \mathrm{NMR}\left(126 \mathrm{MHz}, \mathrm{CDCl}_{3}, \mathrm{RT}\right)$ : $\delta=155.4$ (ArC, 1C), 141.7 (ArC, 1C), 125.5 (ArCH, 1C), 125.4 (ArCH, 1C), 121.3 (ArCH, 1C), 115.6 (ArCH, 1C), $102.6\left(\mathrm{O}_{2} \mathrm{CH}-\right.$ $\left.\mathrm{CH}_{2}-\mathrm{N}, 1 \mathrm{C}\right), 65.0\left(\mathrm{O}-\mathrm{CH}_{2}-\mathrm{CH}_{2}-\mathrm{O}, 2 \mathrm{C}\right), 62.5\left(\mathrm{O}_{2} \mathrm{CH}-\mathrm{CH}_{2}-\mathrm{N}\right.$, 1C), $59.1\left(\mathrm{Ar}-\mathrm{CH}_{2}-\mathrm{N}, 1 \mathrm{C}\right), 42.7\left(\mathrm{~N}-\mathrm{CH}_{3}, 1 \mathrm{C}\right), 34.0\left(\mathrm{C}\left(\mathrm{CH}_{3}\right)_{3}, 1 \mathrm{C}\right)$, $31.7\left(\mathrm{C}\left(\mathrm{CH}_{3}\right)_{3}, 3 \mathrm{C}\right)$.

$\left(\mathbf{L}^{\mathbf{o x}} \mathbf{Z n E t}\right)_{2}$. The ligand $\mathbf{L}^{\mathbf{o x}}-\mathbf{H}(0.56 \mathrm{~g}, 2.00 \mathrm{mmol})$ was dissolved in hexanes $(30 \mathrm{~mL})$ and stirred until the solution became clear. Next, $\mathrm{ZnEt}_{2}(2.00 \mathrm{~mL}, 2.00 \mathrm{mmol})$ was added dropwise at ambient temperature, and the solution was stirred until a white solid precipitated. The resulting suspension was filtered off, washed with hexanes $(10 \mathrm{~mL})$ and dried in vacuo. The resulting white solid was recrystallized from toluene at $-15{ }^{\circ} \mathrm{C}$ to give colourless crystals of $\left(\mathbf{L}^{\mathbf{o x}} \mathbf{Z n E t}\right)_{2}$. Yield $91 \%$ (1.36 g, $1.82 \mathrm{mmol}$ ). Anal. Calcd (Found) for $\mathrm{C}_{36} \mathrm{H}_{58} \mathrm{~N}_{2} \mathrm{O}_{6} \mathrm{Zn}_{2}$ (\%): C, 57.99 (58.11); H, 7.84 (7.96); N, 3.76 (3.89); ${ }^{1} \mathrm{H}$ NMR (500 MHz, $\left.\mathrm{C}_{6} \mathrm{D}_{6}, \mathrm{RT}\right): \delta=7.39-7.35(\mathrm{~m}, \mathrm{ArH}, 2 \mathrm{H}), 7.32(\mathrm{~s}, \mathrm{ArH}$, $2 \mathrm{H}), 7.03(\mathrm{~s}, \mathrm{ArH}, 2 \mathrm{H}), 5.32\left(\mathrm{~s}, \mathrm{O}_{2} \mathrm{CH}-\mathrm{CH}_{2}-\mathrm{N}, 2 \mathrm{H}\right), 4.67$ (s, $\mathrm{Ar}-$ $\left.\mathrm{CH}_{2}-\mathrm{N}, 2 \mathrm{H}\right), 3.98$ (s, $\left.\mathrm{O}_{2} \mathrm{CH}-\mathrm{CH}_{2}-\mathrm{N}, 2 \mathrm{H}\right), 3.51-3.17$ (m, O- $\mathrm{CH}_{2}-$ $\left.\mathrm{CH}_{2}-\mathrm{O}, 8 \mathrm{H}\right), 2.88$ (s, Ar- $\left.\mathrm{CH}_{2}-\mathrm{N}, 2 \mathrm{H}\right), 2.53\left(\mathrm{~s}, \mathrm{O}_{2} \mathrm{CH}-\mathrm{CH}_{2}-\mathrm{N}\right.$, $2 \mathrm{H}), 2.23\left(\mathrm{~s}, \mathrm{~N}-\mathrm{CH}_{3}, 6 \mathrm{H}\right), 1.34\left(\mathrm{t}, J_{\mathrm{HH}}=8.1 \mathrm{~Hz}, \mathrm{CH}_{2} \mathrm{CH}_{3}, 6 \mathrm{H}\right)$, $1.31\left(\mathrm{~s}, \mathrm{C}\left(\mathrm{CH}_{3}\right)_{3}, 18 \mathrm{H}\right), 0.36\left(\mathrm{q}, J_{\mathrm{HH}}=8.1 \mathrm{~Hz}, \mathrm{CH}_{2} \mathrm{CH}_{3}, 4 \mathrm{H}\right)$; ${ }^{13} \mathrm{C}\left\{\mathrm{H}^{1}\right\} \mathrm{NMR}\left(126 \mathrm{MHz}, \mathrm{C}_{6} \mathrm{D}_{6}, \mathrm{RT}\right): \delta=161.6(\mathrm{ArC}-\mathrm{O}, 2 \mathrm{C}), 140.3$ (ArC, 2C), 127.6 (ArCH, 4C), 124.4 (ArC, 2C), 120.4 (ArCH, 2C), $102.5\left(\mathrm{O}_{2} \mathrm{CH}-\mathrm{CH}_{2}-\mathrm{N}, 2 \mathrm{C}\right), 65.4\left(\mathrm{O}-\mathrm{CH}_{2}-\mathrm{CH}_{2}-\mathrm{O}, 2 \mathrm{C}\right), 64.3$ $\left(\mathrm{O}-\mathrm{CH}_{2}-\mathrm{CH}_{2}-\mathrm{O}, 2 \mathrm{C}\right), 63.8\left(\mathrm{Ar}-\mathrm{CH}_{2}-\mathrm{N}, 2 \mathrm{C}\right), 62.6\left(\mathrm{O}_{2} \mathrm{CH}-\mathrm{CH}_{2}-\mathrm{N}\right.$,

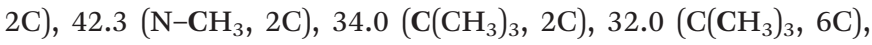
$13.3\left(\mathrm{CH}_{2} \mathrm{CH}_{3}, 2 \mathrm{C}\right),-2.3\left(\mathrm{CH}_{2} \mathrm{CH}_{3}, 2 \mathrm{C}\right)$.

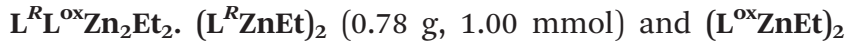
$(0.75 \mathrm{~g}, 1.00 \mathrm{mmol})$ were dissolved in toluene $(20 \mathrm{~mL})$ at room temperature. The solution was stirred and concentrated in vacuo and then placed at $-15{ }^{\circ} \mathrm{C}$. After $24 \mathrm{~h}, \mathbf{L}^{R^{R}} \mathbf{L}^{\mathbf{o x}} \mathbf{Z n}_{2} \mathbf{E} \mathbf{t}_{2}$ was obtained as a white precipitate in an $84 \%$ yield $(1.28 \mathrm{~g}$, $1.68 \mathrm{mmol}$ ). Anal. Calcd (Found) for $\mathrm{C}_{40} \mathrm{H}_{60} \mathrm{~N}_{2} \mathrm{O}_{4} \mathrm{Zn}_{2}$ : C, 62.91 (62.80); H, 7.92 (8.09); N, 3.67 (3.69)\%; ${ }^{1} \mathrm{H}$ NMR (500 MHz, $\left.\mathrm{C}_{6} \mathrm{D}_{6}, \mathrm{RT}\right): \mathrm{L}^{R}$ part: $\delta=7.33\left(\mathrm{dd}, J_{\mathrm{HH}}=8.5,3.0 \mathrm{~Hz}, \mathrm{ArH}, 1 \mathrm{H}\right)$, 7.24-7.11 (m, ArH, 5H), $7.05\left(\mathrm{~d}, J_{\mathrm{HH}}=8.6 \mathrm{~Hz}, \operatorname{ArH}, 1 \mathrm{H}\right), 6.82$ (d, $\left.J_{\mathrm{HH}}=2.3 \mathrm{~Hz}, \mathrm{ArH}, 1 \mathrm{H}\right), 5.03\left(\mathrm{q}, J_{\mathrm{HH}}=6.8 \mathrm{~Hz}, \mathrm{~N}-\mathrm{CH}-\mathrm{CH}_{3}\right.$, $1 \mathrm{H}), 4.79\left(\mathrm{~d}, J_{\mathrm{HH}}=11.9 \mathrm{~Hz}, \operatorname{Ar}-\mathrm{CH}_{2}-\mathrm{N}, 1 \mathrm{H}\right), 3.05\left(\mathrm{~d}, J_{\mathrm{HH}}=\right.$ $\left.11.9 \mathrm{~Hz}, \mathrm{Ar}-\mathrm{CH}_{2}-\mathrm{N}, 1 \mathrm{H}\right), 1.97\left(\mathrm{~s}, \mathrm{~N}-\mathrm{CH}_{3}, 3 \mathrm{H}\right), 1.68\left(\mathrm{~d}, J_{\mathrm{HH}}=\right.$ $\left.7.0 \mathrm{~Hz}, \mathrm{~N}-\mathrm{CH}-\mathrm{CH}_{3}, 1 \mathrm{H}\right), 1.46\left(\mathrm{t}, J_{\mathrm{HH}}=8.1 \mathrm{~Hz}, \mathrm{CH}_{2} \mathrm{CH}_{3}, 3 \mathrm{H}\right)$, $1.14(\mathrm{~s}, 1 \mathrm{H}), 0.46\left(\mathrm{q}, J_{\mathrm{HH}}=8.1 \mathrm{~Hz}, \mathrm{CH}_{2} \mathrm{CH}_{3}, 2 \mathrm{H}\right) ; \mathrm{L}^{\mathrm{ox}}$ part: $\delta=$ 7.35-7.31 (m, ArH, 1H), 7.29 (d, $\left.J_{\mathrm{HH}}=8.1 \mathrm{~Hz}, \mathrm{ArH}, 1 \mathrm{H}\right), 7.06$ $\left(\mathrm{d}, J_{\mathrm{HH}}=2.9 \mathrm{~Hz}, \mathrm{ArH}, 1 \mathrm{H}\right), 5.31\left(\mathrm{dd}, J_{\mathrm{HH}}=6.2,2.3 \mathrm{~Hz}, \mathrm{O}_{2} \mathrm{CH}-\right.$ $\left.\mathrm{CH}_{2}-\mathrm{N}, 1 \mathrm{H}\right), 4.72\left(\mathrm{~d}, J_{\mathrm{HH}}=12.1 \mathrm{~Hz}, \mathrm{Ar}-\mathrm{CH}_{2}-\mathrm{N}, 1 \mathrm{H}\right), 4.00$ (dd, $\left.J_{\mathrm{HH}}=12.8,1.8 \mathrm{~Hz}, \mathrm{O}_{2} \mathrm{CH}-\mathrm{CH}_{2}-\mathrm{N}, 1 \mathrm{H}\right), 3.53-3.40\left(\mathrm{~m}, \mathrm{O}-\mathrm{CH}_{2}-\right.$ $\left.\mathrm{CH}_{2}-\mathrm{O}, 2 \mathrm{H}\right), 3.33-3.18\left(\mathrm{~m}, \mathrm{O}-\mathrm{CH}_{2}-\mathrm{CH}_{2}-\mathrm{O}, 2 \mathrm{H}\right), 2.91\left(\mathrm{~d}, J_{\mathrm{HH}}=\right.$ $\left.12.1 \mathrm{~Hz}, \mathrm{Ar}-\mathrm{CH}_{2}-\mathrm{N}, 1 \mathrm{H}\right), 2.53\left(\mathrm{dd}, J_{\mathrm{HH}}=12.7,6.3 \mathrm{~Hz}, \mathrm{O}_{2} \mathrm{CH}-\right.$ $\left.\mathrm{CH}_{2}-\mathrm{N}, 1 \mathrm{H}\right), 2.24\left(\mathrm{~s}, \mathrm{~N}-\mathrm{CH}_{3}, 3 \mathrm{H}\right), 1.32\left(\mathrm{~s}, \mathrm{C}\left(\mathrm{CH}_{3}\right)_{3}, 9 \mathrm{H}\right), 1.31$ (t, $\left.J_{\mathrm{HH}}=7.9 \mathrm{~Hz}, \mathrm{CH}_{2} \mathrm{CH}_{3}, 3 \mathrm{H}\right), 0.32$ (q, $J_{\mathrm{HH}}=8.1 \mathrm{~Hz}, \mathrm{CH}_{2} \mathrm{CH}_{3}$, $2 \mathrm{H}) ;{ }^{13} \mathrm{C}$ NMR $\left(126 \mathrm{MHz}, \mathrm{C}_{6} \mathrm{D}_{6}, \mathrm{RT}\right): \delta=\mathrm{L}^{R}$ part: 161.5 (ArC-O, 1C), 140.5 (ArC-C, 1C), 136.3 (ArC-CH, 1C), 130.3 (ArCH, 1C), 128.5 ( $\mathrm{ArCH}, 4 \mathrm{C}), 128.4$ (ArCH, 1C), 127.6 (ArCH, 1C), 124.7 $\left(\mathrm{ArC}-\mathrm{CH}_{2}, 1 \mathrm{C}\right), 120.1(\mathrm{ArCH}, 1 \mathrm{C}), 64.5(\mathrm{~N}-\mathrm{CH}-\mathrm{Ar}, 1 \mathrm{C}), 61.5(\mathrm{~N}-$

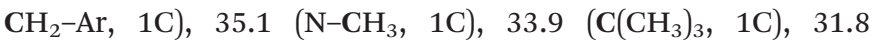
$\left(\mathrm{C}\left(\mathrm{CH}_{3}\right)_{3}, 3 \mathrm{C}\right), 19.9\left(\mathrm{CH}_{3}-\mathrm{CH}, 2 \mathrm{C}\right), 13.4\left(\mathrm{CH}_{2}-\mathrm{CH}_{3}, 1 \mathrm{C}\right),-2.1$ $\left(\mathrm{CH}_{2}-\mathrm{CH}_{3}, 1 \mathrm{C}\right) ; \mathrm{L}^{\mathrm{ox}}$ part $\delta=161.5(\mathrm{ArC}-\mathrm{O}, 1 \mathrm{C}), 140.4$ (ArC, 1C), 128.7 (ArCH, 1C), $127.4(\mathrm{ArCH}, 1 \mathrm{C}), 124.5$ (ArC, 1C), 120.2 (ArCH, 1C), $102.5\left(\mathrm{O}_{2} \mathrm{CH}-\mathrm{CH}_{2}-\mathrm{N}, 1 \mathrm{C}\right), 65.4\left(\mathrm{O}-\mathrm{CH}_{2}-\mathrm{CH}_{2}-\mathrm{O}\right.$, 1C), $64.3\left(\mathrm{O}-\mathrm{CH}_{2}-\mathrm{CH}_{2}-\mathrm{O}, 1 \mathrm{C}\right), 64.0\left(\mathrm{Ar}-\mathrm{CH}_{2}-\mathrm{N}, 1 \mathrm{C}\right), 62.7$ $\left(\mathrm{O}_{2} \mathrm{CH}-\mathrm{CH}_{2}-\mathrm{N}, 1 \mathrm{C}\right), 42.3\left(\mathrm{~N}-\mathrm{CH}_{3}, 1 \mathrm{C}\right), 34.0\left(\mathrm{C}\left(\mathrm{CH}_{3}\right)_{3}, 1 \mathrm{C}\right), 32.0$ $\left(\mathrm{C}\left(\mathrm{CH}_{3}\right)_{3}, 3 \mathrm{C}\right), 13.6\left(\mathrm{CH}_{2} \mathrm{CH}_{3}, 1 \mathrm{C}\right),-1.7\left(\mathrm{CH}_{2} \mathrm{CH}_{3}, 1 \mathrm{C}\right)$.

\section{Representative procedure for solution polymerization}

In a typical polymerization experiment, the solution of an initiator $\left(\mathbf{L}^{\mathbf{o x}} \mathbf{Z n E t}\right)_{2}$ dissolved in $\mathrm{CH}_{2} \mathrm{Cl}_{2}$ was placed in a Schlenk flask, and external alcohol in a stoichiometric amount $\left(\mathbf{L}^{\mathbf{o x}} \mathbf{Z n E t}\right)_{2} / \mathrm{ROH}=0.5 / 1(\mathrm{ROH}=\mathrm{MeOH}, \mathrm{BzOH})$ was added $\left(0.35 \mathrm{mmol}\right.$ of $\left(\mathbf{L}^{\mathbf{o x}} \mathbf{Z n E t}\right)_{2}$ and $0.70 \mathrm{mmol}$ of ROH$)$. Then, after 10 minutes, the monomer L-LA $(7.00 \mathrm{mmol})$ was added at a fixed molar ratio $\left(\mathbf{L}^{\mathbf{o x}} \mathbf{Z n E t}\right)_{2} / \mathrm{L}-\mathrm{LA} / \mathrm{ROH}=0.5 / n / 1 ; n=20,50$, 100. The resulting solution was stirred at room temperature for a prescribed time until the reaction was completed. At certain time intervals ( $c a .10 \mathrm{~min}$ ), about $1 \mathrm{~mL}$ aliquots were removed, precipitated with hexanes and dried in vacuo. The conversion was determined by observing the ${ }^{1} \mathrm{H}$ NMR resonances of the polymer and monomer after dissolving the precipitates in $\mathrm{C}_{6} \mathrm{D}_{6}$. When the reaction was completed, an excess of hexanes was added to the reaction mixture. Filtration and vacuum drying yielded a white polymer. The resulting solid was dissolved in $\mathrm{CH}_{2} \mathrm{Cl}_{2}$, and the polymer was precipitated with an excess of cold methanol. The polymer was collected by filtration, washed with methanol to remove the non-reacted monomer, and dried under reduced pressure. The reaction mixtures were prepared in a glove-box, and subsequent operations were performed using standard Schlenk techniques.

\section{Crystallography}

X-ray diffraction data for $\left(\mathbf{L}^{\mathbf{o x}} \mathbf{Z n E t}\right)_{2}$ and $\left(\mathbf{L}^{R^{R}} \mathbf{E}^{\mathbf{c y}} \mathbf{Z n}_{2} \mathbf{E t}_{2}\right)$ crystals were collected on a Xcalibur diffractometer with a Sapphire2 detector (MoK $\alpha$ radiation; $\lambda=0.71073 \AA$ ) or a Xcalibur diffractometer with an Onyx detector (see ESI†) with a $\omega$ scan technique at $100 \mathrm{~K}$. The data collection and processing utilized the CrysAlis suit of programs. ${ }^{46}$ Space groups were determined based on systematic absences and intensity statistics. Lorentz, polarization and analytical absorption corrections were applied. The structure was solved by direct methods and refined by full-matrix least-squares on $F^{2}$. All calculations were 
performed using the SHELXTL-2013 suite of programs. ${ }^{47}$ All non-hydrogen atoms were refined with anisotropic displacement parameters. Hydrogen atoms were placed at their calculated positions. Before the last cycle of refinement, all $\mathrm{H}$ atoms were fixed and were allowed to ride on their parent atoms. Thermal ellipsoid plots were prepared with 50\% probability displacements for non-hydrogen atoms using the Mercury 3.1 program. ${ }^{48}$ All data have been deposited with the Cambridge Crystallographic Data Centre CCDC 1511741 for $\left(\mathbf{L}^{\mathbf{o x}} \mathbf{Z n E t}\right)_{2}$ and 1511742 for $\mathbf{L}^{R} \mathbf{L}^{\mathbf{c y}} \mathbf{Z n}_{2} \mathbf{E t}_{2}$.

\section{Computational details}

All density functional theory (DFT) calculations were performed with the Gaussian 03 program suite. ${ }^{49}$ The geometries of the complexes and ligands were optimized (Fig. S13-20, Tables S2-9 in ESI $\dagger$ ) using B3LYP density functional theory and the $6-31 G^{* *}$ basis sets, implemented in Gaussian 03 on all atoms. $^{50,51}$ The starting geometries of the complexes $\left(\mathbf{L}^{\mathbf{o x}} \mathbf{Z n E t}\right)_{2}$ and $\left(\mathbf{L}^{\mathbf{o x}}\right)_{2} \mathbf{Z n}$ were generated from their crystal structures. Structures of all isomers of the calculated complexes were first optimized in vacuo.

\section{Results and discussion}

The well-defined aminophenolate zinc complexes with a single-site motif determined by X-ray analysis are limited to merely a few examples. ${ }^{29,37,38,40}$ All of them possess a di-tert- butyl phenol core in the ancillary ligands, and their coordination properties are controlled by backbone variations on nitrogen atoms. The modification of the aryl core or amine substituents with sterically bulky groups has been routinely used to restrict the aggregation of metal aryloxides formed during an alcoholysis. Recently, we published two new zinc examples with aminonaphtholate ancillary ligands, and our results indicated that a sizable group next to the hydroxyl of the aminophenol/aminonaphthol ligands is the reason for the mixture of metal complexes forming. ${ }^{45}$ The nuances in the synthetic procedure can be used to create a complex of planned structural motif. Thereby, the design of new periphery groups, according to these requirements, constitutes a continuously interesting synthetic strategy.

\section{DFT assisted implications for complex design}

Recently, the family of stable aminophenolate zinc dimers and homoleptic monomers have been synthesized in our group (Scheme 3). ${ }^{33,41,43,44}$ Both the experimental data and DFT calculations indicate that aminophenol ligands $\left(\mathrm{L}^{R / c y}\right.$ with free ortho-positions of phenol ring) prefer a dimeric alkylzinc compound formation. This dimeric structure is retained in the solution, and this dependence is evidenced by DFT calculations that show that the energy for the monomeric forms (LZnEt or $\mathbf{L}_{2} \mathbf{Z n}$ ) of the zinc complexes with ortho-free ligands $\mathrm{L}^{\text {cy }}$ and $\mathrm{L}^{R}$ is evidently higher than for the dimers (LZnEt) (Scheme 3, left side and Fig. 1, grey and white bars). Instead, for analogous ancillary ligands $\left(€^{\mathrm{cy}}\right.$, the same substituent on
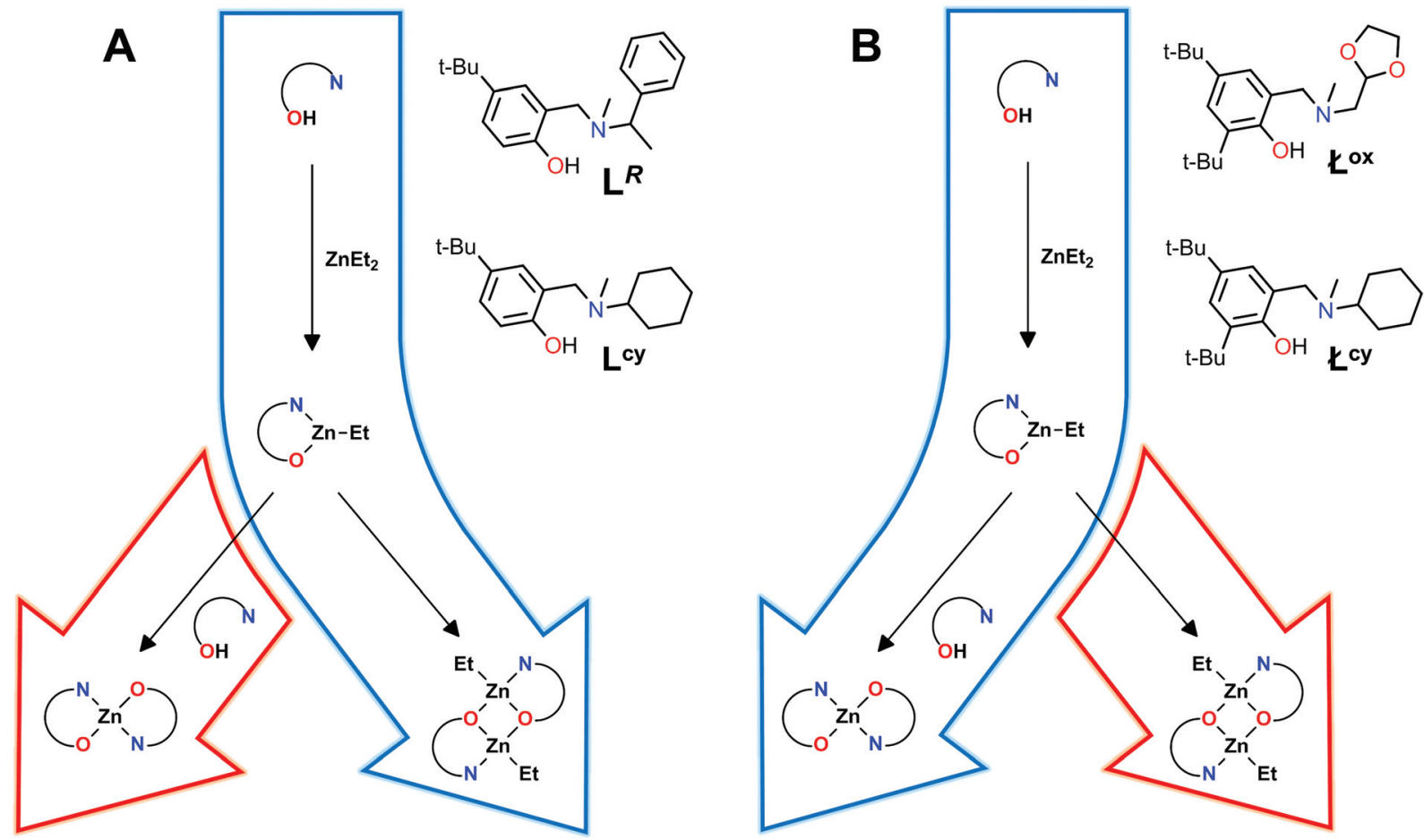

Scheme 3 Synthetic procedure for aminophenolate zinc complexes. Blue arrow - favourable synthesis; (A) favourable heteroleptic dimers formation; (B) favourable homoleptic monomers formation. L-para-tert-Butylphenyl core, $Ł$-ortho,para-di-tert-butylphenyl core, ${ }^{R, c y, ~ o x}$ substituents on amine arm. 

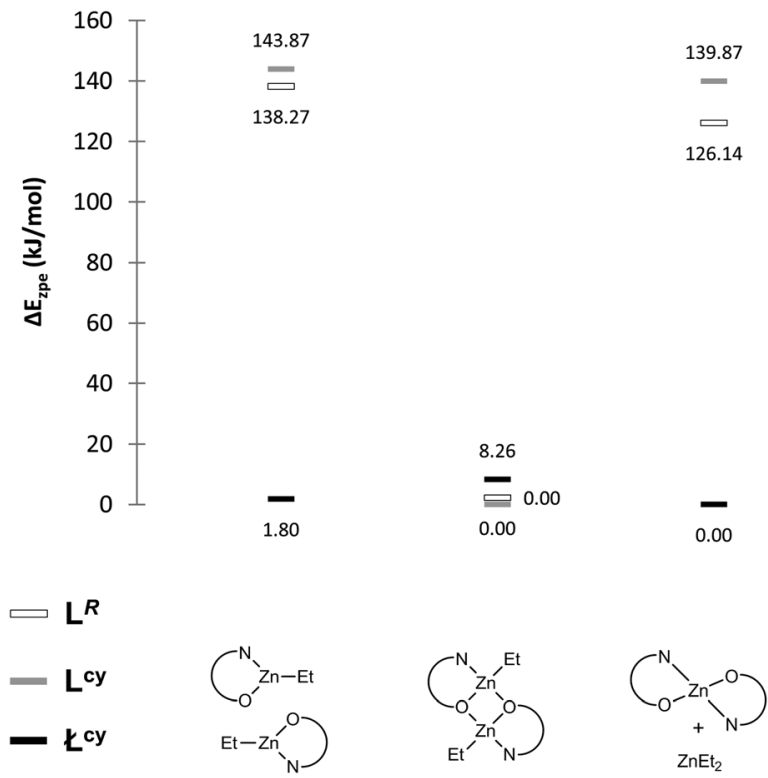

Fig. 1 The calculated relative energies in the gas-phase for the geometrically optimized zinc compounds.

$\mathrm{N}$-donor atom as for $\mathrm{L}$ ), the presence of the bulky tert-butyl groups in the ortho-position leads to homoleptic $\mathrm{Ł}_{2} \mathrm{Zn}$ bischelate complex crystallization (Scheme 3, right side). Despite that only the homoleptic monomer precipitated from the reaction mixture, the calculated small differences between the energy of the potential monomers, $\mathrm{t}_{2} \mathrm{Zn}, \mathrm{ZnEt}_{2}$, $\mathrm{EZnEt}$ compared to the dimers syn/anti (LZnEt) ${ }_{2}$, explain their potential coexistence in the solution (Fig. 1, black bars).

The homoleptic complex $\left(\mathbf{L}^{\mathbf{o x}}\right)_{2} \mathbf{Z n}$ containing a hemilable amino-arm with a dioxolane ring has been subjected to our previous structural study by X-ray analysis and DFT calculations. ${ }^{41}$ This complex is flexible, and during the optimization, we obtained nineteen structures. Moreover, one of them, possessing a "fully open" structure (both oxolane arms pendant), is dominant at higher temperatures, and this isomer forms in the presence of an alcohol an active catalytic system for the ROP of lactides (structure B in Fig. 2). Instead, at room temperature, a mixture of the "closed" and "half-opened" (with one pendant oxolane arm) structures are present.

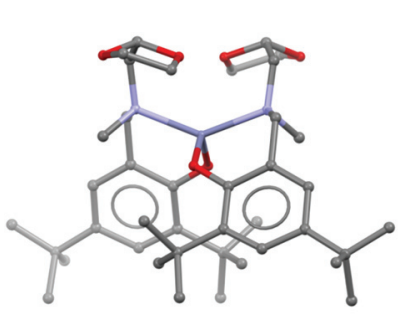

A

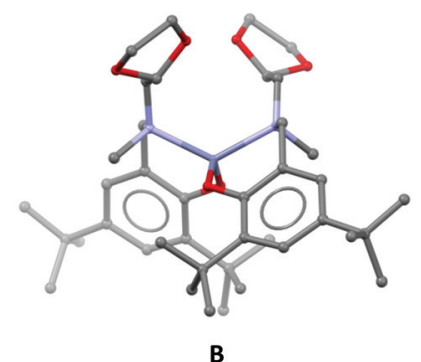

B
Fig. 2 Isomers of $\left(\mathfrak{t}^{\mathrm{ox}}\right)_{2} \mathrm{Zn}$ : (A) inactive in ROP and (B) active form.
However, at the time, we supposed that the heteroleptic species ( $\left.\mathbf{L}^{\mathbf{o x}} \mathbf{Z n E t}\right)_{\mathbf{2}} / \mathbf{L}^{\mathbf{o x}} \mathbf{Z n E t}$ were absent in the solution because in the reaction between $\mathrm{ZnEt}_{2}$ and $\mathrm{E}^{\mathrm{ox}}-\mathrm{H}$, the homoleptic monomer $\left(\mathbf{L}^{\mathbf{o x}}\right)_{2} \mathbf{Z n}$ was the only isolated product. Now, we have verified this result, and the potential heteroleptic dimers $\left(\mathbf{L}^{\mathbf{o x}} \mathbf{Z n E t}\right)_{2}$ and appropriate monomers have been investigated by DFT calculations (see details in the Experimental section and ESI $\dagger$ ). The results and the optimized geometrical structures are presented in Fig. 3 (red bars, DFT optimized structures see ESI $\dagger$ ). The energies of the generated heteroleptic dimers $\Delta E\left(\mathbf{L}^{\mathbf{o x}} \mathbf{Z n E t}\right)_{2}$, heteroleptic monomers $\Delta E\left(\mathbf{L}^{\mathbf{o x}} \mathbf{Z n E t}\right)$, and homoleptic species $\Delta E\left[\left(\mathbf{(}^{\mathbf{o x}}\right)_{2} \mathbf{Z n}+\mathrm{ZnEt}_{2}\right]$ are similar, especially for "closed" and "opened" isomers in adequate couples of homomonomers (50.29 and $49.22 \mathrm{~kJ} \mathrm{~mol}^{-1}$ ) and heterodimers (8.73 and $0.00 \mathrm{~kJ} \mathrm{~mol}^{-1}$ ), as shown in Fig. 3. These additional new theoretical data explain the predictable coexistence of all possible homo/heteroleptic compounds in the reaction mixture due to the low energetic cost of the transformation between them. Then, precipitation/crystallization of e.g. homoleptic $\left(\mathbf{L}^{\mathbf{o x}}\right)_{2} \mathbf{Z n}$ may be enough to move the reaction equilibrium towards formation of solely one product of the $\mathrm{E}^{\mathrm{ox}}-\mathrm{H}$ and $\mathrm{ZnEt}_{2}$ reaction. Likely, it may be the reason that the crystallization of "single-site" type zinc complexes is difficult for aminophenolate complexes bearing ligands with bulky substituents in the ortho-position of phenol.

Relying on our previously published results, ${ }^{43}$ the exclusive formation of a heteroleptic zinc complex should be possible for an analogue ligand with a free ortho-position $\mathbf{L}^{\mathbf{o x}}-\mathbf{H}$. Therefore, to verify this assumption, we performed gas-phase geometrical optimization of the new dimeric complex $\left(\mathbf{L}^{\mathbf{o x}} \mathbf{Z n E t}\right)_{\mathbf{2}}$ by means of DFT calculations. The relative energies $\Delta E_{\mathrm{ZPE}}$ calculated for the optimized conformers are presented in Table S1-S5 in the ESI† and in Fig. 3 (green bars). Additionally, the potential monomeric forms of the zinc complex with the $\mathrm{L}^{\mathrm{ox}}$ ligand have been investigated. The relative energy values for the monomer $\mathrm{L}^{\text {ox }}$ ZnEt and homoleptic species $\left(\mathrm{L}^{\mathrm{ox}}\right)_{2} \mathrm{Zn}$ with $\mathrm{ZnEt}_{2}$ are in this case higher than that for the preferable heteroleptic dimer $\left(\mathbf{L}^{\mathbf{o x}} \mathbf{Z n E t}\right)_{2}$. These theoretical studies indicated that the heteroleptic dimer $\left(\mathbf{L}^{\mathbf{o x}} \mathbf{Z n E t}\right)_{\mathbf{2}}$ should be the most stable species in the reaction mixture (both isomers in closed and opened forms), so we decided to verify the theoretical outcome by experimental tests.

\section{Synthesis and characterization of compounds}

The new aminophenolate proligand $\mathbf{L}^{\mathbf{o x}}-\mathbf{H}$ was prepared by a standard one-pot Mannich condensation between para-substituted phenol, formaldehyde and 2-methylaminomethyl-1,3dioxolane in methanol in a similar way as described in previous literature. ${ }^{43}$ The proligand was obtained in high yields (91\%) and was characterized by standard elemental analysis, MS and spectroscopic methods. The ${ }^{1} \mathrm{H}$ and ${ }^{13} \mathrm{C}\left\{{ }^{1} \mathrm{H}\right\}$ NMR studies gave well-resolved resonances for all proton and carbon environments, indicating the high purity of the isolated compound (ESI, Fig. S1 and S2 $\dagger$ ). Next, the $\mathbf{L}^{\mathbf{o x}} \mathbf{- H}$ was used for zinc complex synthesis in the reaction with $\mathrm{ZnEt}_{2}$ in hexanes at room temperature (Scheme 4). 

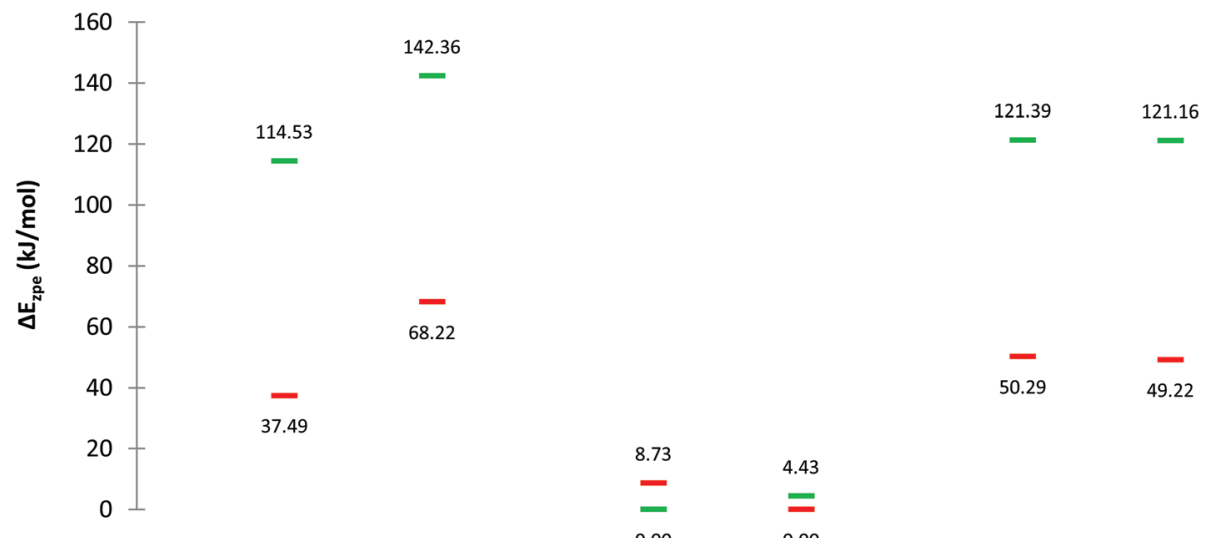

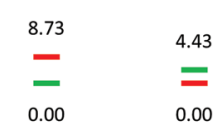
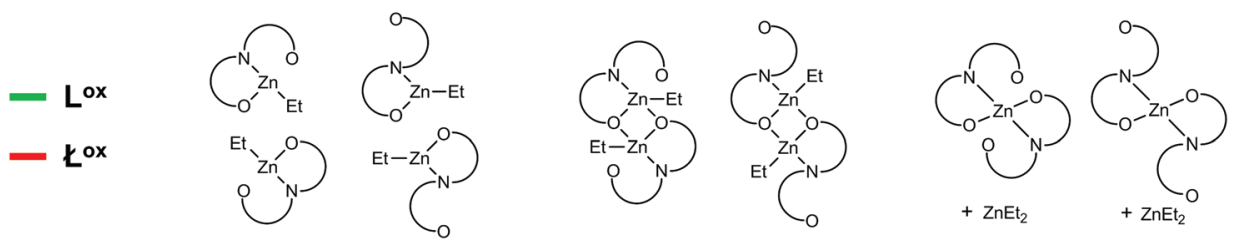

Fig. 3 The relative calculated energies in the gas-phase for the geometrically optimized heteroleptic dimers (LZnEt) 2 , couple of homoleptic monomers $(\mathrm{L})_{2} \mathrm{Zn}$ with $\mathrm{ZnEt}_{2}$ and monomers $\mathrm{LZnEt} ;\left(\mathrm{L}=\mathrm{L}^{\mathrm{ox}}, \mathrm{t}^{\mathrm{ox}}\right.$ ). Below schematic structures of possible complexes with the ancillary ligand $\mathrm{L}^{\mathrm{ox}}, \mathrm{t}^{\mathrm{ox}}$ (open and closed forms).

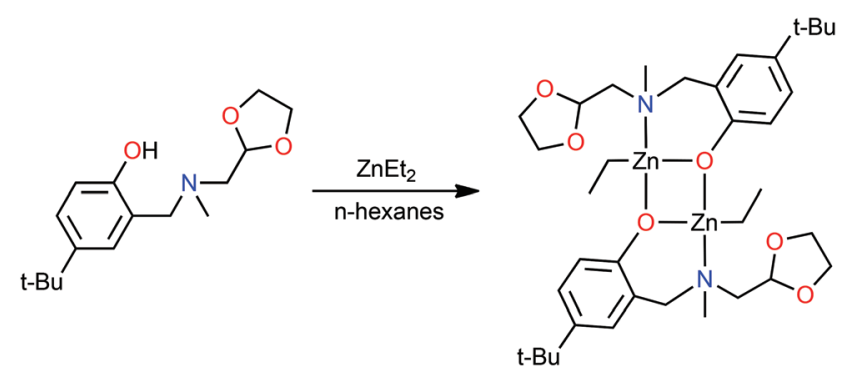

Scheme 4 Synthesis of a zinc complex with the aminophenolate ligand $\mathrm{L}^{\mathrm{ox}}-\mathrm{H}$.

In the first attempt, stoichiometric amounts of $\mathbf{L}^{\mathbf{o x}}-\mathbf{H}$ and $\mathrm{ZnEt}_{2}$ (1/1) were used for the isolation of the molecular heteroleptic zinc complex ( $\left.\mathbf{L}^{\mathbf{o x}} \mathbf{Z n E t}\right)_{2}$. Next, we tried to obtain a homoleptic zinc compound $\left(\mathbf{L}^{\mathbf{o x}}\right)_{2} \mathbf{Z n}$, however, it appeared impossible, both with the use of an appropriate molar ratio of reagents $\left(\mathbf{L}^{\mathbf{o x}}-\mathbf{H} / \mathrm{ZnEt}_{2}=2 / 1\right)$ and when reactions were carried out in an excess of $\mathbf{L}^{\mathbf{o x}} \mathbf{- H}$ proligand. This result correlated strongly with the presented theoretical prediction, which shows that the dimeric complex is the most favourable structural motif.

The obtained dimer $\left(\mathbf{L}^{\mathbf{o x}} \mathbf{Z n E t}\right)_{\mathbf{2}}$ is well-soluble in toluene, thf, $\mathrm{CH}_{2} \mathrm{Cl}_{2}$ and insoluble in aliphatic hydrocarbons. The complex was characterized by ${ }^{1} \mathrm{H}$ and ${ }^{13} \mathrm{C}$ NMR spectroscopy and X-ray crystallography. The distinctive ${ }^{1} \mathrm{H}$ NMR signals of $\left(\mathbf{L}^{\mathbf{o x}} \mathbf{Z n E t}\right)_{2}$ include broad singlets (methylene backbone $\mathrm{Ar}-\mathrm{CH}_{2}-\mathrm{N}, \mathrm{CH}-\mathrm{CH}_{2}-\mathrm{N}$ and methine protons $-\mathrm{CH}$ at 4.67, 2.88; 3.98, 2.53 and $5.32 \mathrm{ppm}$, respectively) (Fig. 4 and $\mathrm{ESI}^{\dagger}$ ). The

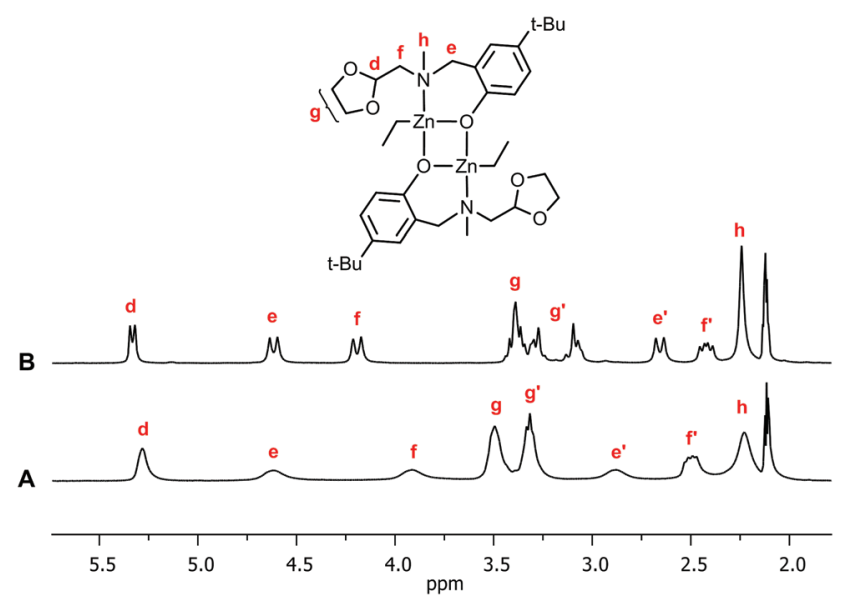

Fig. 4 Fragment of ${ }^{1} \mathrm{H}$ NMR spectrum of ( $\left.{ }^{o x} \mathrm{ZnEt}\right)_{2}$ at: (a) $298 \mathrm{~K}$ and (b) $223 \mathrm{~K}$.

spectrum includes typical features of $\left(\mathbf{L}^{\mathbf{o x}} \mathbf{Z n E t}\right)_{2}$ : singlets at $2.23 \mathrm{ppm}\left(\mathrm{N}-\mathrm{CH}_{3}\right)$ and $1.31(t-\mathrm{Bu})$, multiplets for oxolane $-\mathrm{CH}_{2}-$ protons at $3.51-3.17 \mathrm{ppm}$ and a group of aromatic protons: multiplet at 7.39-7.35 ppm and singlets at 7.32 and $7.03 \mathrm{ppm}$. The ${ }^{1} \mathrm{H}$ NMR spectrum also shows a triplet at 1.34 and a quartet at 0.36 belonging to $\mathrm{Zn}-\mathrm{CH}_{2}-\mathrm{CH}_{3}$; the triplet is obscured by the singlet of the tert-butyl protons. Broad singlets form appropriate doublets and multiplets in the ${ }^{1} \mathrm{H}$ NMR spectrum obtained at $223 \mathrm{~K}$ (Fig. 4B). All signals are distinguished in a COSY spectrum (see $\mathrm{ESI}^{\dagger}$ ).

The dimeric structure of $\left(\mathbf{L}^{\mathbf{o x}} \mathbf{Z n E t}\right)_{2}$ in solution was confirmed by DOSY NMR. The estimated translation diffusion 
Table 1 Selected bond distances $(\AA \AA)$ and angles $\left({ }^{\circ}\right)$ for $\left(\mathrm{L}^{\mathrm{ox}} \mathrm{ZnEt}\right)_{2}$

\begin{tabular}{|c|c|c|}
\hline Atoms & $\left(\mathbf{L}^{\mathbf{o x}} \mathrm{ZnEt}\right)_{2}$ (X-ray) & $\left(\mathbf{L}^{\mathrm{ox}} \mathrm{ZnEt}\right)_{2}(\mathrm{DFT})$ \\
\hline \multicolumn{3}{|c|}{ Bond distance $[\AA]$} \\
\hline Zn-C17 & $1.980(2)$ & 1.9813 \\
\hline Zn1-O1 & $2.009(2)$ & 2.0234 \\
\hline $\mathrm{Zn} 1-\mathrm{O} 1^{\prime \mathrm{i}}$ & $2.093(2)$ & 2.0843 \\
\hline Zn1-N1 & $2.156(2)$ & 2.1770 \\
\hline $\mathrm{Zn} 1-\mathrm{Zn} 1^{\mathrm{i}, a}$ & $3.111(2)$ & 3.1469 \\
\hline $\mathrm{O} 1-\mathrm{O} 1^{\mathrm{i}, a}$ & $2.675(3)$ & 2.6404 \\
\hline $\mathrm{Zn} 1-\mathrm{O} 2^{\mathrm{i}, a}$ & $2.779(2)$ & 2.7381 \\
\hline \multicolumn{3}{|l|}{ Angels [ํ] } \\
\hline $\mathrm{C} 17-\mathrm{Zn} 1-\mathrm{O} 1$ & $128.92(8)$ & 130.172 \\
\hline $\mathrm{C} 17-\mathrm{Zn} 1-\mathrm{O} 1^{\mathrm{i}}$ & $115.98(9)$ & 119.636 \\
\hline $\mathrm{O} 1-\mathrm{Zn} 1-\mathrm{O} 1^{\mathrm{i}}$ & $81.39(7)$ & 79.986 \\
\hline $\mathrm{C} 17-\mathrm{Zn} 1-\mathrm{N} 1^{\mathrm{i}}$ & $127.25(9)$ & 122.980 \\
\hline $\mathrm{O} 1-\mathrm{Zn} 1-\mathrm{N} 1^{\mathrm{i}}$ & $97.33(7)$ & 99.382 \\
\hline $\mathrm{O} 1^{\mathrm{i}}-\mathrm{Zn} 1-\mathrm{N} 1^{\mathrm{i}}$ & $91.85(7)$ & 91.600 \\
\hline $\mathrm{Zn} 1-\mathrm{O} 1-\mathrm{Zn} 1^{\mathrm{i}}$ & $98.61(7)$ & 100.005 \\
\hline
\end{tabular}

$\mathrm{i}=-x+1,-y+1,-z+1 .{ }^{a}$ Values in parentheses refer to the nonbonding interactions.

coefficient $D_{\exp }$ in deuterated benzene was $6.54 \times 10^{-10} \mathrm{~m}^{2} \mathrm{~s}^{-1}$ (calculated $D_{\mathrm{f}}^{\mathrm{SES}}=6.64 \times 10^{-10} \mathrm{~m}^{2} \mathrm{~s}^{-1}$ for DFT optimised structure). In order to compare the structure in the solid state and in solution, the adequate diffusion coefficients were estimated from the solid state structure determined by X-ray crystallography and DFT study. The obtained values for the diffusion coefficient of ( $\left.\mathbf{L}^{\mathbf{o x}} \mathbf{Z n E t}\right)_{2}$ estimated by experimental X-ray, NMR and theoretical study were comparable.

\section{X-ray study of $\left(\mathrm{L}^{\mathrm{ox}} \mathrm{ZnEt}\right)_{2}$}

The colourless crystals of $\left(\mathbf{L}^{\mathbf{o x}} \mathbf{Z n E t}\right)_{2}$, suitable for X-ray analysis, were grown by slow evaporation of a toluene solution. The solid state structure of (LZnEt $)_{2}$ was determined as outlined in Table 1 and Fig. 5.

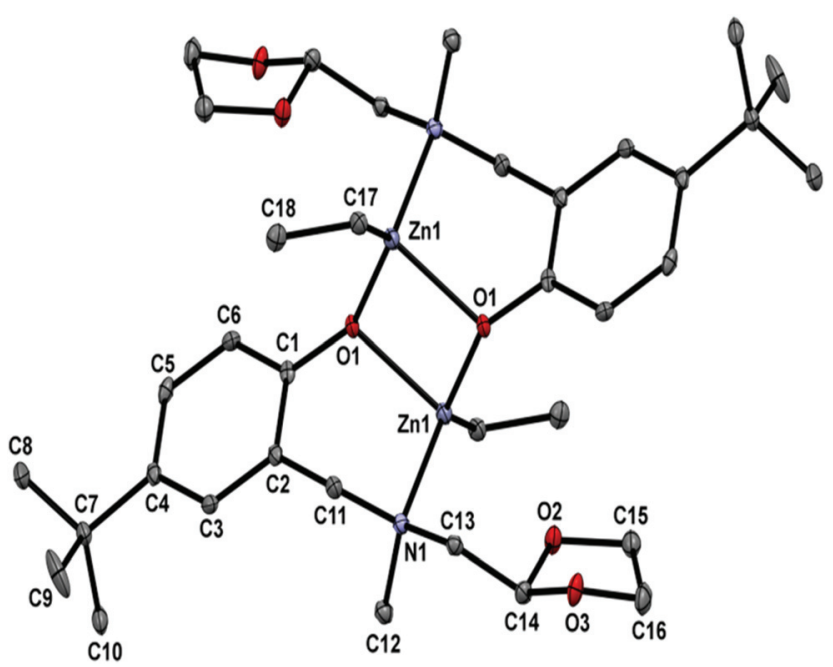

Fig. 5 The molecular structure of $\left(\mathrm{L}^{\mathrm{ox}} \mathrm{ZnEt}\right)_{2}$. The thermal ellipsoids are drawn at the $30 \%$ probability level. $\mathrm{H}$ atoms are omitted for the sake of clarity.
The X-ray single-crystal structure of $\left(\mathbf{L}^{\mathbf{o x}} \mathbf{Z n E t}\right)_{2}$ showed dimeric species with tetrahedral zinc centres bridged via phenyl oxygen atoms with ethyl groups located trans to each other. The nitrogen and phenyl oxygen atoms of the aminophenolate ligand form a six-membered metalacycle with a twisted, boat-shaped conformation, but the ether oxygen atoms of the oxolane rings failed to chelate, leaving ethereal functionality free in the crystal. All the bond distances between zinc and $\mathrm{O}, \mathrm{N}, \mathrm{C}$ atoms are typical and range: $\mathrm{Zn}-\mathrm{O}$, 2.014(3) and 2.095(3); Zn-N, 2.160(3); Zn-C, 1.976(4) A. The distances and angles are all comparable with bond lengths and angles observed for similar complexes described in the literature. $^{37,38,43,44}$ The geometric parameters for $\left(\mathbf{L}^{\mathbf{o x}} \mathbf{Z n E t}\right)_{2}$ obtained by DFT calculations were compared with the experimental data (Table 1). The agreement between the optimized geometric structure and the experimental data from the X-ray analysis is fully satisfactory, and the only essential difference may be the position of the ethyl group bonding to the zinc centres (Fig. 6). As it can be seen, the lowest $\Delta E\left[\left(\mathbf{L}^{\mathbf{o x}} \mathbf{Z n E t}\right)_{2}\right]$ value found for the optimized isomer $\left(\mathbf{L}^{\mathbf{o x}} \mathbf{Z n E t}\right)_{2}$ (see Fig. 3) has been adequate for a solid-state structure, so the experimental data confirm the theoretical studies, indicating that the heteroleptic dimer is the most stable species in the reaction mixture.

As already mentioned, the most common single-site initiators for the ROP process are heteroleptic metal alkoxides (sometimes formed in situ by the reaction of an appropriate alcohol and alkylmetal complex, for example LZnEt). The $\left(\mathbf{L}^{\mathbf{o x}} \mathbf{Z n E t}\right)_{\mathbf{2}}$ dimer possesses all these structural features; therefore, after the in situ alcoholysis it was used as an initiator for the ROP of lactides. Unfortunately, the ROP was slow even at an elevated temperature $\left(60^{\circ} \mathrm{C}\right)$, and $\left(\mathbf{L}^{\mathbf{o x}} \mathbf{Z n E t}\right)_{2}$ polymerized 20 equiv. of L-LA in the presence of $\mathrm{MeOH}$ or benzyl alcohol (as an external alcohol) in 5 days. The poor polymerization result excluded $\left(\mathbf{L}^{\mathbf{o x}} \mathbf{Z n E t}\right)_{2}$ from the cluster of interesting

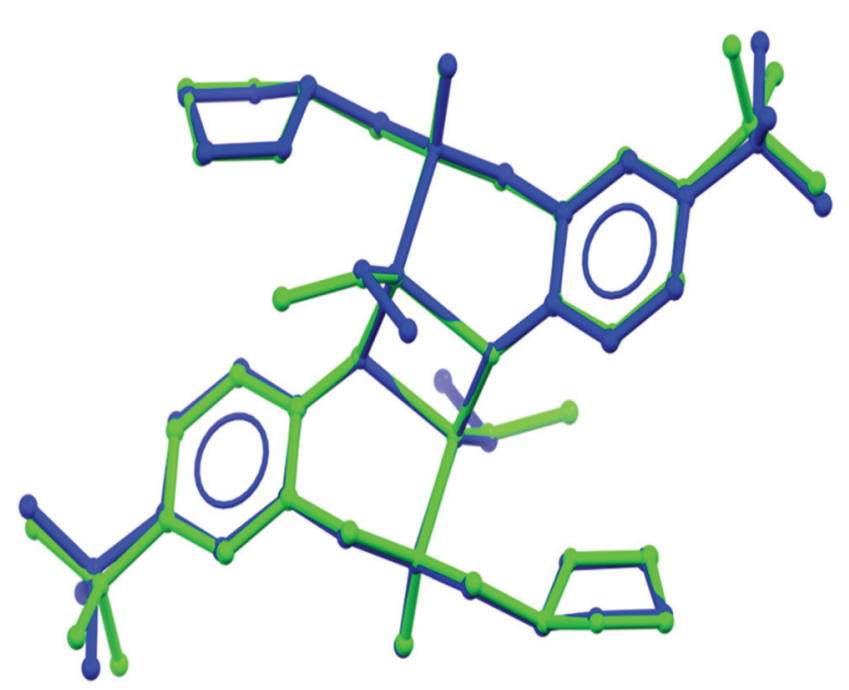

Fig. 6 Superimposed crystallographic (green) and DFT calculated (blue) structures of $\left(\mathrm{L}^{\mathrm{ox}} \mathrm{ZnEt}\right)_{2}$. 
initiators for the ROP of lactides. Therefore, the focus of our attention has now been shifted towards the verification of this unexpectedly low catalytic reactivity.

The well-defined, confirmed by X-ray analysis aminophenolate complexes of the single-site motif are rare, but one of the most active in the ROP is Hillmyer's and Tolman's complex $\left(\mathbf{L}^{\mathbf{T}} \mathbf{Z n O E t}\right)_{2}$, shown in Scheme 5 . It was synthesized via the reaction of the monomer $\mathrm{七}^{\mathrm{T}} \mathrm{ZnEt}$ with ethanol at room temperature. ${ }^{29}$ Surprisingly, the chiral ethyl zinc analogue $\mathrm{七}^{\mathrm{M}} \mathrm{ZnEt}$, obtained by Mehrkhodavandi, ${ }^{34}$ was inert towards alcohols with the use of ethanol, methanol, isopropanol, and this complex reacted only with phenol or hydrochloric acid (Scheme 5). The reactivity/inertness of the mentioned complexes may be explained by the lability (dynamic behaviour)/ stability of the amine functionality of the ligand, which is crucial during alcoholysis. Hence, we verified this literature data by DFT. The relative calculated energies for the model zinc complexes obtained for Tolman and Mehrkhodavandi initiators are presented in Fig. 7 (for details see, ESI $\dagger$ ). Although the heteroleptic monomeric species $\mathrm{E}^{\mathrm{T} / \mathrm{M}} \mathrm{ZnEt}$ are preferred for both examples, the "open structures" facilitating molecular fitting between reagents are energetically disfavoured for $\mathrm{t}^{\mathrm{M}} \mathrm{ZnEt}$, which confirms the difficulties during alcoholysis. The large energy difference between "open" and "closed" monomers for $\mathrm{七}^{\mathrm{T}} \mathrm{ZnEt}\left(0.00\right.$ vs. $\left.101.01 \mathrm{~kJ} \mathrm{~mol}^{-1}\right)$ and the relatively low energy cost for the formation of an open dimer $\left(\mathbf{L}^{\mathbf{T}} \mathbf{Z n E t}\right)_{2}$ may indicate more advanced but effective transformation pathways between them. In all the considered zinc complexes, the theoretical study significantly confirms the experimental data. This indicates that complexes that are easily transformable coexisted in solution, and homo/heteroleptic species containing a flexible amine arm, may act as a potential precatalysts in ROP. The presented zinc complex with the aminophenolate ligand $\iota^{\mathrm{ox}}$ additionally confirms this phenomenon.

Nevertheless, the dimer $\left(\mathbf{L}^{\mathbf{o x}} \mathbf{Z n E t}\right)_{2}$ is unreactive towards stoichiometric amounts of methanol and alcoholysis according to the procedure published by us recently. ${ }^{42}$ To clarify the easiness/difficulties in the coordination of alcohols to the discussed zinc dimers, in the next stage, we optimized the structures of these species with methanol (Scheme 6). For dimers with our ancillary ligands $\left(\mathrm{L}^{R}, \mathrm{~L}^{\mathrm{cy}}\right)$, two coordination modes are possible to delineate. A similar proposition is clear for Tolman's complex, and all of them are able to easily undergo further intramolecular alcoholysis via a reaction between the coordinated ligands ( $\mathrm{ROH}$ and $\mathrm{Et}$ ). However, the coordination of methanol for complexes with $\mathrm{L}^{\text {ox }}$ or $\mathrm{L}^{\mathrm{M}}$ is difficult to verify by DFT calculations because generation of appropriate adducts requires decoordination of nitrogen atoms. Whereas, the experimental data indicated that it is impossible. These calcu-

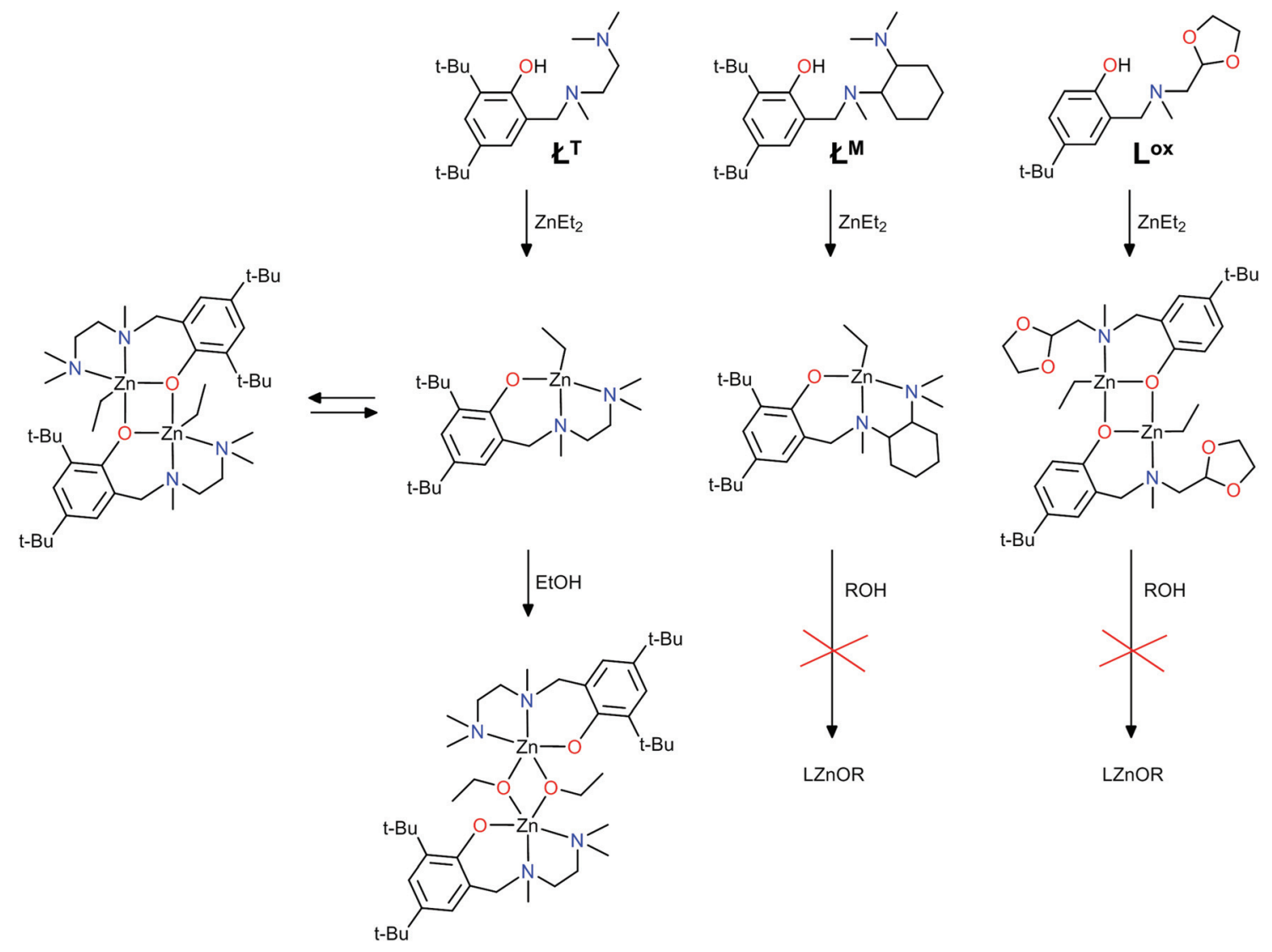

Scheme 5 Syntheses of "single-site" type initiators. 

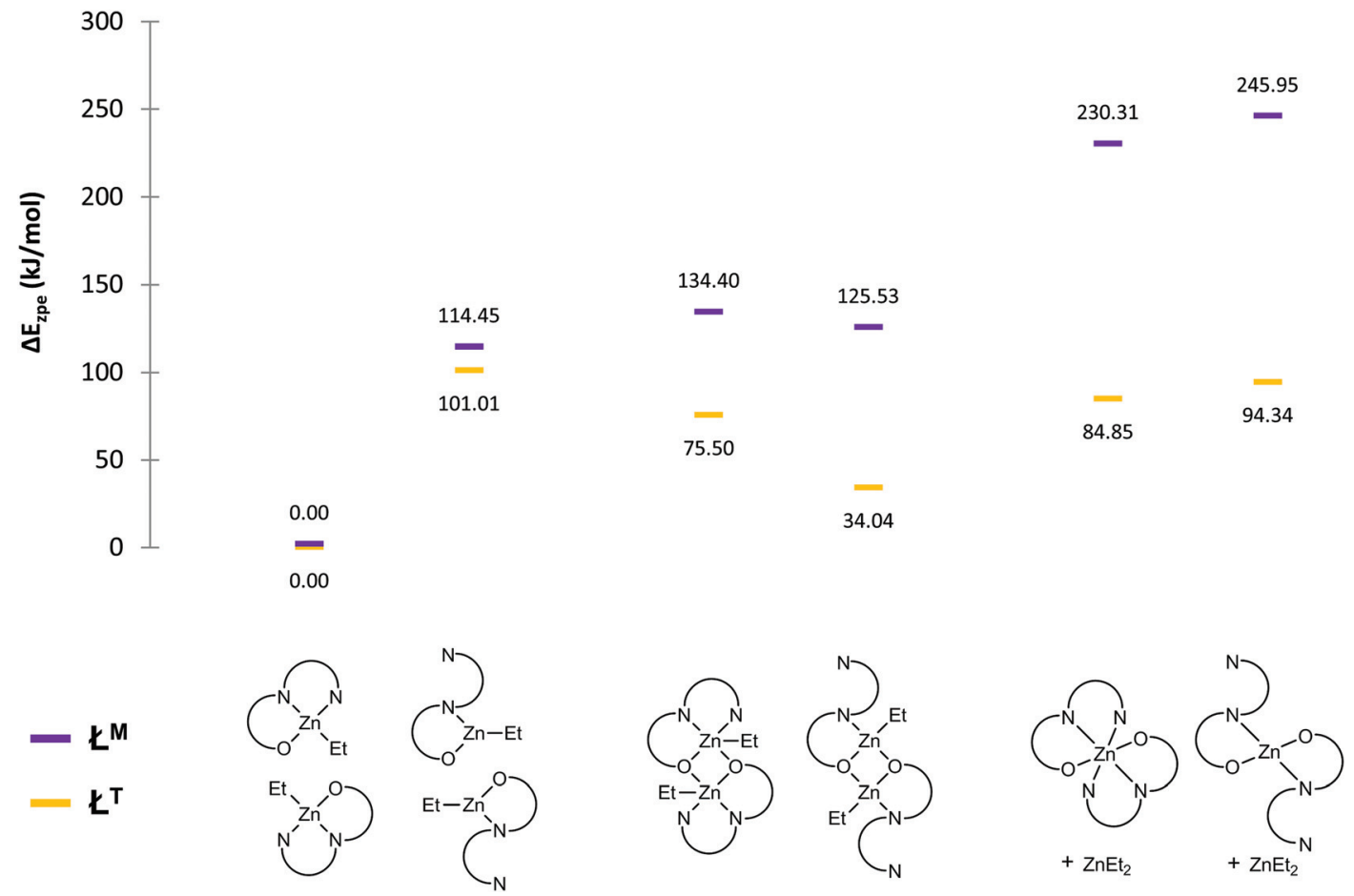

Fig. 7 The relative calculated energies in the gas-phase for the geometrically optimized heteroleptic dimers (LZnEt) 2 , couple of homoleptic monomers $(\mathrm{L})_{2} \mathrm{Zn}$ with $\mathrm{ZnEt}_{2}$ and monomers $\mathrm{LZnEt} ; \mathrm{t}^{\top}$ - Tolman's ligand - yellow line; $\mathrm{t}^{\mathrm{M}}$ - Mehrkhodavandi ligand - violet line.

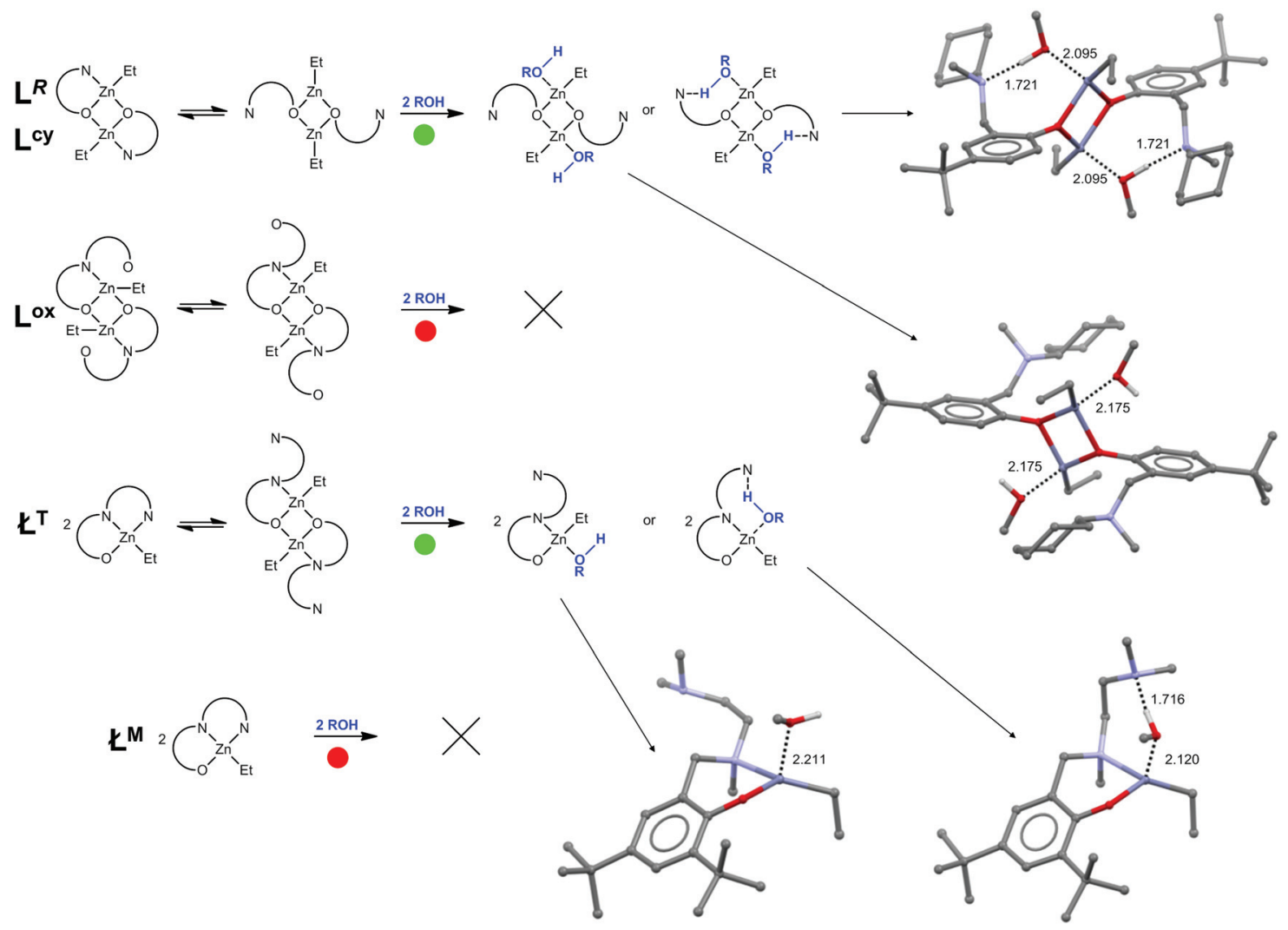

Scheme 6 Structures of LZnEt/(LZnEt) $)_{2}$ species in the presence of an alcohol molecule (schematic on the left, DFT optimized on right), green circle means easy coordination, red circle - difficult/impossible. 
lations may serve as direct support for the prediction of the catalytic activity of the related complexes. The energy profile of the intermediates for methoxy-zinc species accessible during alcoholysis is shown in Fig. 8. The calculations for corresponding structural motifs indicated that complexes with flexible ancillary ligands easily undergo alcoholysis and form appropriate alkoxy species.

The simple modification of the ancillary ligand by expurgation of the tert-butyl group gave an excellent structural motif, agreeable with the single-site precursor but insignificantly active towards the ROP of lactides. Here, this conclusion was also verified by theoretical study. Additionally, DFT data gave the leads for modification of the complex (synthesized or calculated) for improved catalytic activity. For example, the last chance for our dimer $\left(\mathbf{L}^{\mathbf{o x}} \mathbf{Z n E t}\right)_{2}$ to be an active catalyst could be its dynamic behaviour in solution, but the same stable dimeric structure, as in the solid state, is retained after dissolution. Therefore, "the last bastion of hope" for the synthesis of an "active in ROP" complex based on the $\mathrm{L}^{\text {ox }}$ ligand was the use of the recently described by us "zebra reaction", which is a useful procedure for heterodimeric zinc complex formation, as shown in Fig. 9. This procedure is likely supported by the presented DFT calculations indicating the possibility of a potential
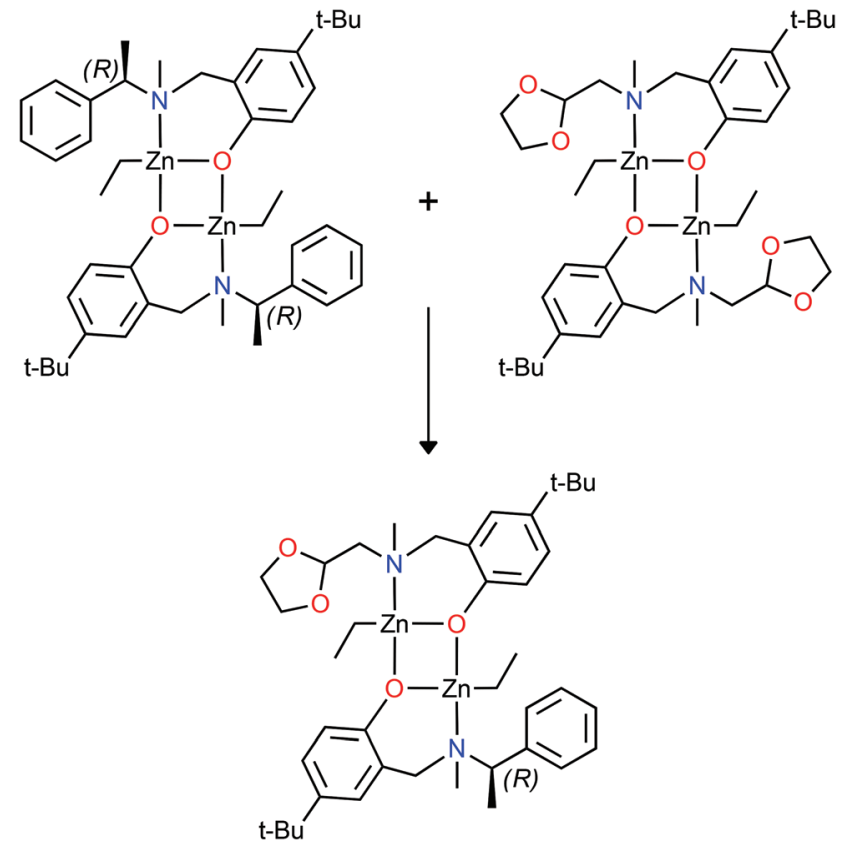

Fig. 9 Synthesis of heterodimeric zinc complex $\left(\mathrm{L}^{R} \mathrm{~L}^{\mathrm{ox}} \mathrm{Zn}_{2} \mathrm{Et}_{2}\right)$ using the zebra reaction protocol.

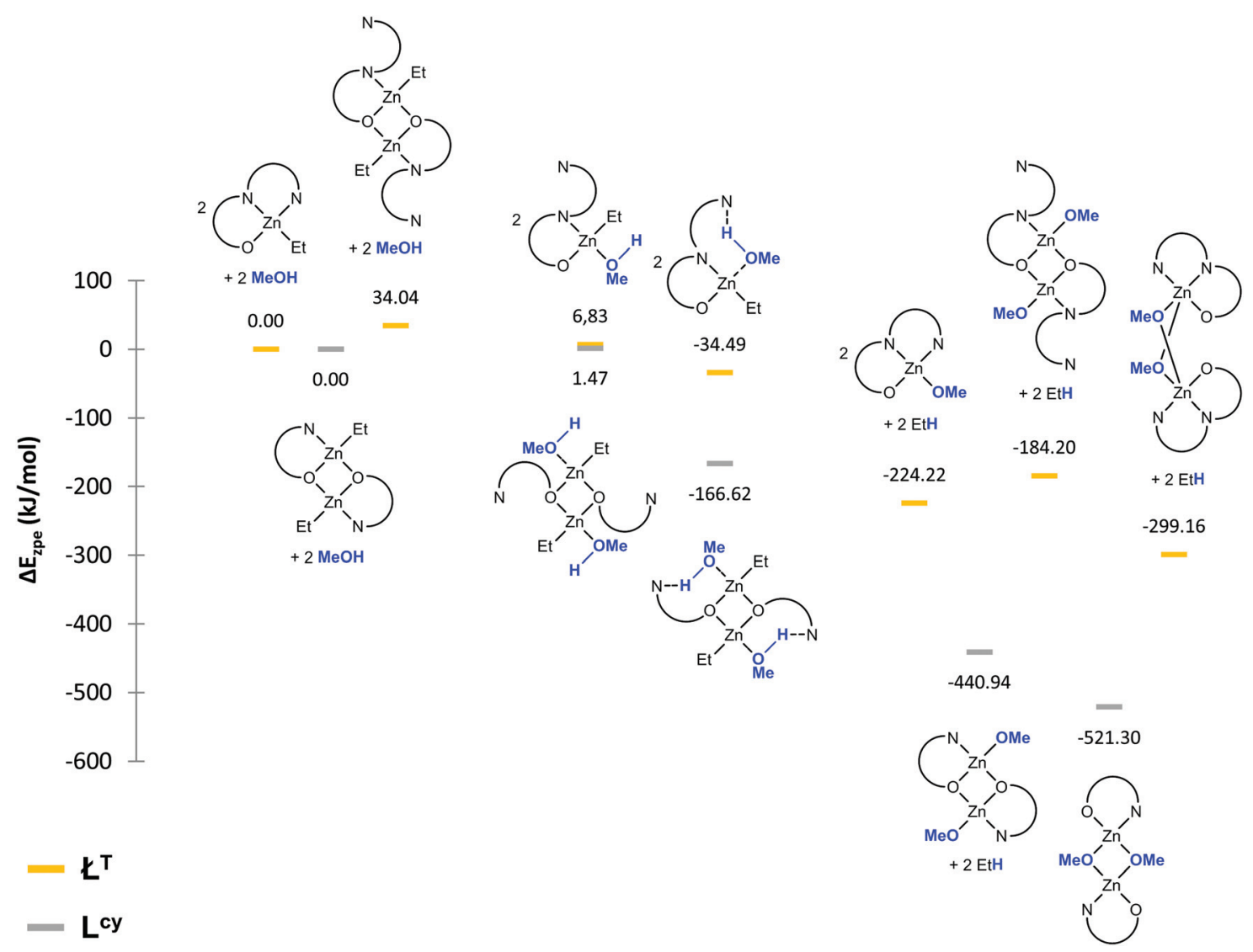

Fig. 8 The relative calculated energies in the gas-phase for the geometrically optimized zinc species potentially formed during methanolysis of LZnEt/(LZnEt) 2 . $\mathrm{L}^{\mathrm{T}}$ Tolman ligand - yellow line; $\mathrm{L}^{\mathrm{cy}}-$ grey line. 
reaction between two homodimers; one of them is a zinc complex with the chiral ligand $\mathrm{L}^{R}{ }^{44}$ This complex $\left(\mathbf{L}^{\boldsymbol{R}} \mathbf{Z n E t}\right)_{2}$ well matches the unreactive $\left(\mathbf{L}^{\mathbf{o x}} \mathbf{Z n E t}\right)_{2}$ because it is the most dynamic in the solution homodimer from the family of our zinc complexes, which can easily recognize $\left(\mathbf{L}^{\mathbf{o x}} \mathbf{Z n E t}\right)_{2}$ by the coordination fitting code. The selective formation of a new heterodimer made by DFT inspiration is presented in Fig. 9.

The old $\left(\mathbf{L}^{\boldsymbol{R}} \mathbf{Z n E t}\right)_{2}$ and new $\left(\mathbf{L}^{\mathbf{o x}} \mathbf{Z n E t}\right)_{2}$ homodimers reacted readily to form the corresponding zinc heterodimer
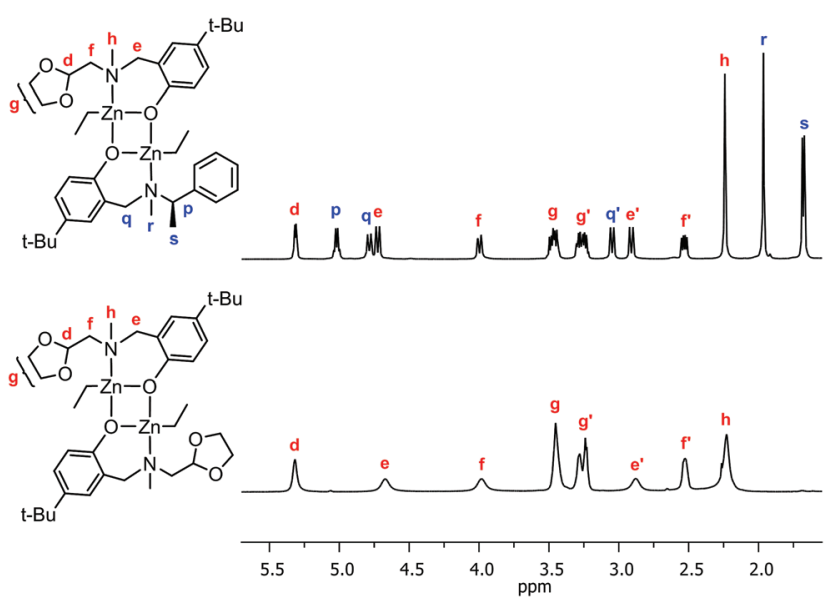

Fig. 10 The fragment of ${ }^{1} \mathrm{H}$ NMR spectrum of the substrate and product of the zebra reaction.
$\left(\mathbf{L}^{R} \mathbf{L}^{\mathbf{o x}} \mathbf{Z} \mathbf{n}_{2} \mathbf{E t} \mathbf{t}_{2}\right)$, and although the X-ray analysis is not available, this complex presents clear NMR spectra confirming the expected structural motif (Fig. 10 and ESI $\dagger$ ).

The polymerization test for the new heterodimer $\mathbf{L}^{R} \mathbf{L}^{\mathbf{o x}} \mathbf{Z n}_{2} \mathbf{E t}_{\mathbf{2}}$ was positive. The initiator formed during an alcoholysis reaction between $\mathbf{L}^{{ }^{R}} \mathbf{L}^{\mathbf{o x}} \mathbf{Z n}_{\mathbf{2}} \mathbf{E t}_{\mathbf{2}}$ and methanol polymerized 100 equiv. of L-LA yielding PLA with a narrow PDI $=1.14$. The molecular weights of the PLAs were higher than expected for PLA-100 based on the initial monomer-to-catalyst ratio (Table 2, entry 5). The divergence from the anticipated molecular weights (in this example PLA-185 according to $M_{\mathrm{n}}$ determined by GPC) is not accidental, but it may be explained by one effective metal centre that is active during ROP. The fragment $\mathrm{L}^{\mathrm{ox}} \mathrm{ZnEt}$ plays the role of the inactive ancillary "metalloligand" stabilizing the working ROP second fragment $\mathrm{L}^{R} \mathrm{ZnEt}$. What is worth emphasizing is that the homodimer with the ancillary ligand $\mathrm{L}^{R}$ is not so precise (PLA-100, PDI $=1.29$ and 1.34 for $\mathrm{L}^{S}$ respectively; Table 2, entry 1-2).

It is worth noting that the idea of this reaction and the method for activation of the zinc complex are possible by DFT selection. The optimized structure of the $\left(\mathbf{L}^{R} \mathbf{L}^{\mathbf{o x}} \mathbf{Z n}_{\mathbf{2}} \mathbf{E} \mathbf{t}_{\mathbf{2}}\right)$ complex with the methanol molecule confirms the experimental results (Fig. 11 and Scheme 7).

Based on the successful synthesis of the $\left(\mathbf{L}^{R} \mathbf{L}^{\mathbf{o x}} \mathbf{Z n}_{\mathbf{2}} \mathbf{E t} \mathbf{t}_{\mathbf{2}}\right)$ complex, we tried to design another heterodimer from theoretical studies. We would like to freeze by "zebra reaction" the heteroleptic motif $\mathrm{E}^{\mathrm{cy}} \mathrm{ZnEt}$, which is impossible to isolate by simple synthetic strategy (Fig. 1 and Scheme 2). The reaction

Table 2 ROP of LA initiated by zinc complexes [I]

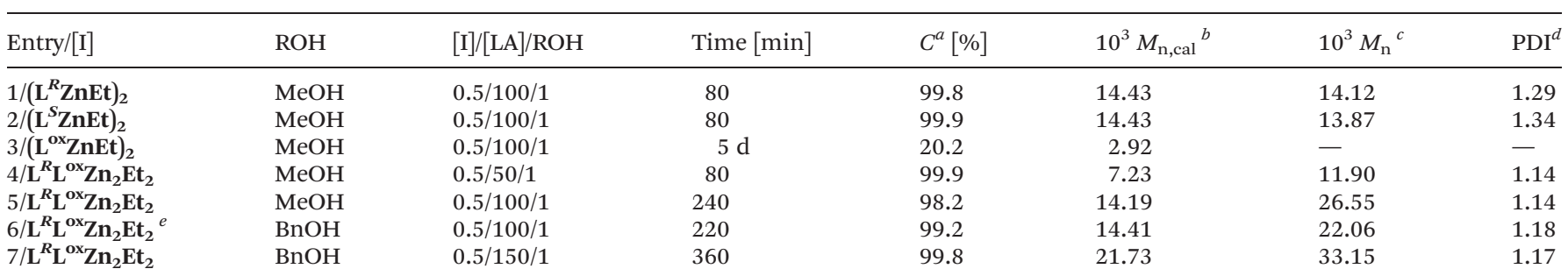

Reaction conditions: $\mathrm{CH}_{2} \mathrm{Cl}_{2} ; T=25{ }^{\circ} \mathrm{C} .{ }^{a}$ Obtained from ${ }^{1} \mathrm{H}$ NMR. ${ }^{b}$ Calculated from $M_{\mathrm{n}, \text { cal }}=[\mathrm{L}-\mathrm{LA}]_{\mathrm{o}} /[\mathrm{ROH}]_{\mathrm{o}} \times C \times 144.13+M_{\mathrm{ROH}} \cdot{ }^{c}$ Determined by GPC calibrated versus polystyrene standards and corrected by a factor of 0.58 according to literature recommendations. ${ }^{52}{ }^{d}$ Obtained from GPC. ${ }^{e}$ rac-LA was used to give atactic PLA $\left(P_{\mathrm{i}}=0.48\right.$ determined by ${ }^{1} \mathrm{H}\left\{{ }^{1} \mathrm{H}\right\}$ NMR).
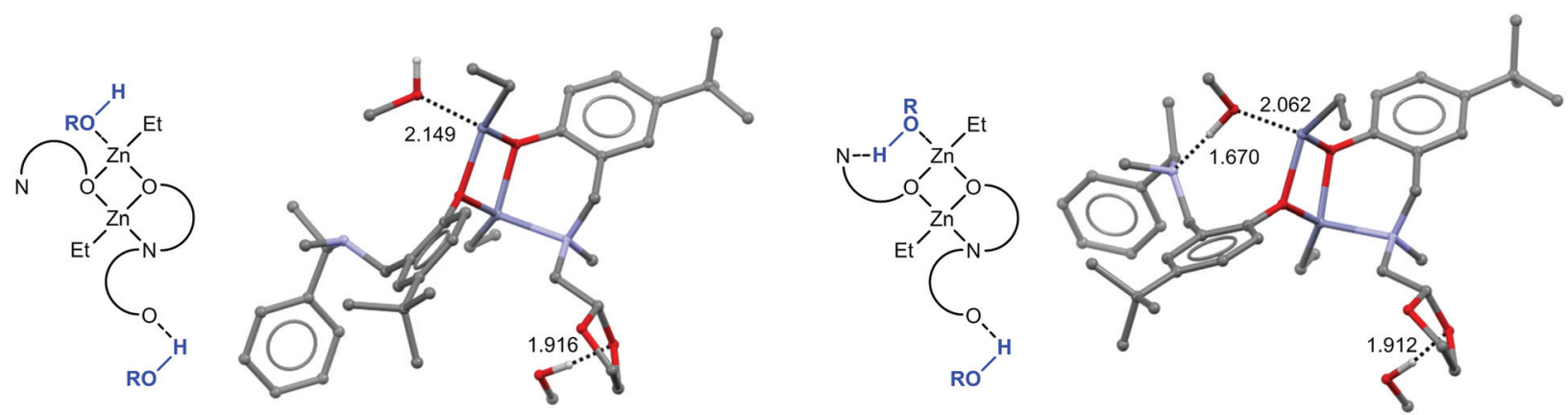

Fig. 11 The structures of $\left(\mathrm{L}^{R} \mathrm{~L}^{\mathrm{ox}} \mathrm{Zn}_{2} \mathrm{Et}_{2}\right)$ complex in the presence of $\mathrm{MeOH}$ molecules (schematic on left, DFt optimized on right). 


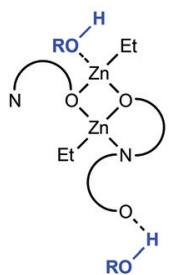

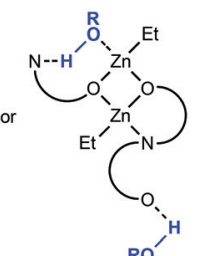

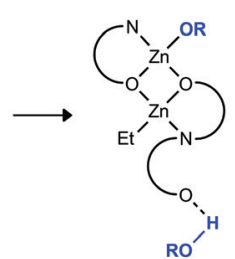

I

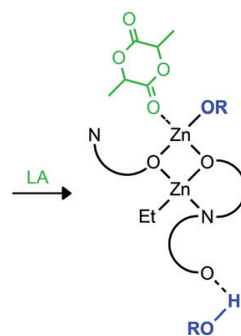

II

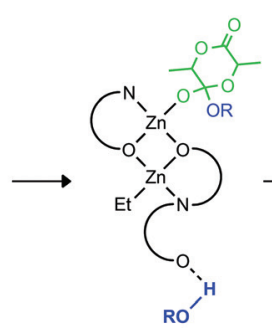

III

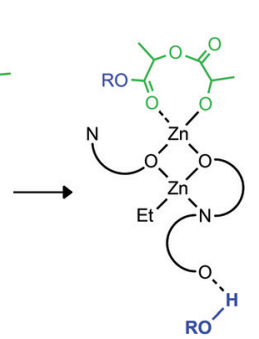

IV

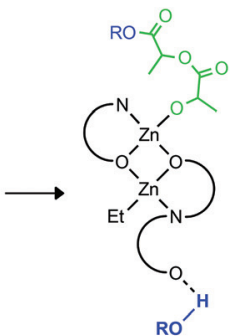

V

Scheme 7 Schematic for the first cycle in the ROP of lactide initiated by zinc dimer $\left(\mathrm{L}^{R} \mathrm{~L}^{\mathrm{ox}} \mathrm{Zn}_{2} \mathrm{Et} \mathrm{t}_{2}\right)$. I - active species, II - coordination of lactide, III - insertion, IV - ring opening, V - decoordination of lactyl-lactate ester group.

between $\mathrm{ZnEt}_{2}$ and $\mathrm{E}^{\mathrm{cy}}$-H gave a mixture of complexes in the parent toluene solution (all coexisted complexes are well soluble), which clearly transformed to one homoleptic $\left(\mathrm{E}^{\mathrm{cy}}\right)_{2} \mathrm{Zn}$ in hexanes. Therefore, we performed the "zebra reaction" between the chiral homodimer $\left(\mathbf{L}^{\boldsymbol{R}} \mathbf{Z n E t}\right)_{2}$ and in situ prepared a mixture of $\mathrm{ZnEt}_{2}$ and $\mathrm{E}^{\mathrm{cy}}-\mathrm{H}$. In this case, the active homodimer was recognized by the well-tailored reagent $(\mathbf{L Z n E t})_{2}$,

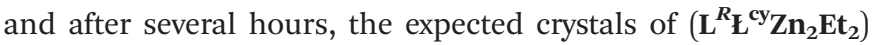
appeared (Fig. 12 and 13, for X-ray structure see ESI $\dagger$ ).

The structure of the new unique heterodimer $\left(\mathbf{L}^{R^{2}} \mathbf{L}^{\mathrm{cy}_{\mathbf{Z}}} \mathbf{Z n}_{2} \mathbf{E t}_{2}\right)$ has been confirmed by X-ray analysis (Fig. 13); however, dissolution of the crystals in toluene resulted in a mixture of dimer $\left(\mathbf{L}^{R} \mathbf{Z n E t}\right)_{2}$ and monomer $\left(\mathrm{E}^{\mathrm{cy}}\right)_{2} \mathrm{Zn}$. This data proves that heteroleptic complexes with the $\mathrm{E}^{\mathrm{cy}}$ ligand are really present in the reaction mixture. Superimposed solid-state structures of $\left(\mathbf{L}^{R} \mathbf{L}^{\mathrm{cy}} \mathbf{Z n}_{2} \mathbf{E t}_{2}\right)$ and previously published $\left(\mathbf{L}^{R} \mathbf{L}^{\mathrm{cy}} \mathbf{Z n}_{2} \mathbf{E t}_{2}\right)^{44}$ show that the interposition of the sizable tert-butyl hindrance in the ortho-position of the phenol core provoked drift in the methyl-

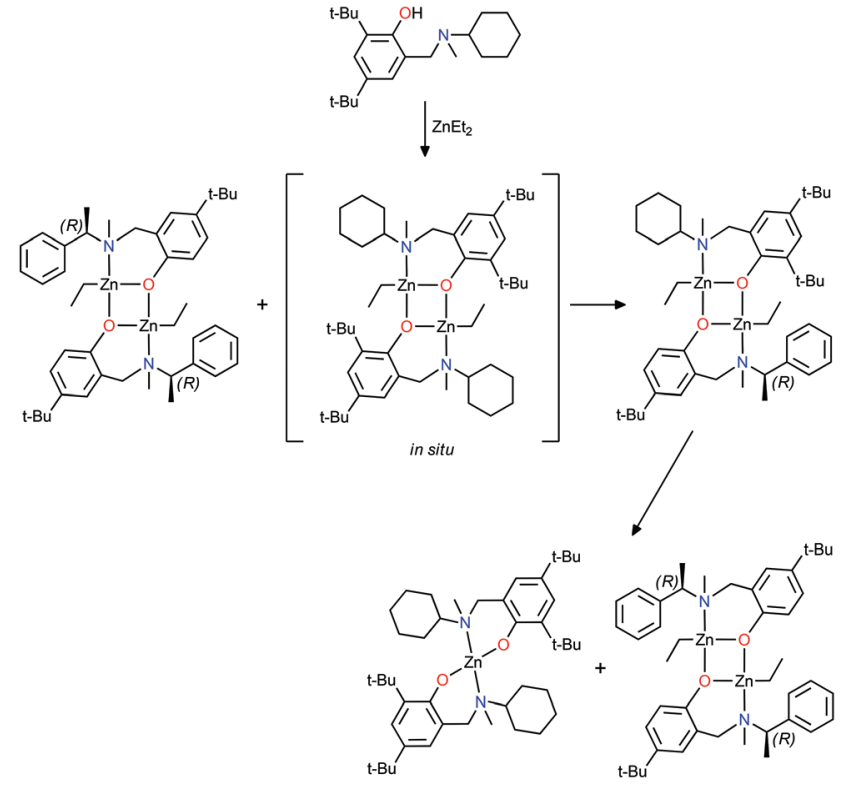

Fig. 12 Synthesis of heterodimeric zinc complex $L^{R} \mathfrak{L}^{\mathrm{cy}} \mathrm{Zn}_{2} \mathrm{Et}_{2}$ using a "zebra reaction" strategy.

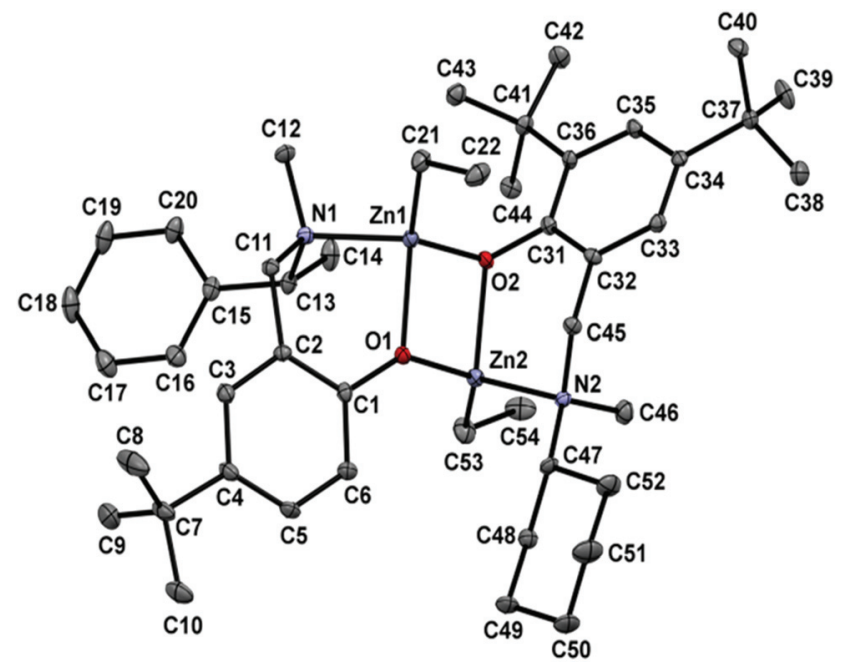

Fig. 13 The molecular structure of $\left(\mathrm{L}^{R} \mathrm{cy}^{\mathrm{cy}} \mathrm{Zn}_{2} \mathrm{Et} \mathrm{t}_{2}\right)$. The thermal ellipsoids are drawn at a $30 \%$ probability level. $\mathrm{H}$ atoms are excluded for the sake of clarity.

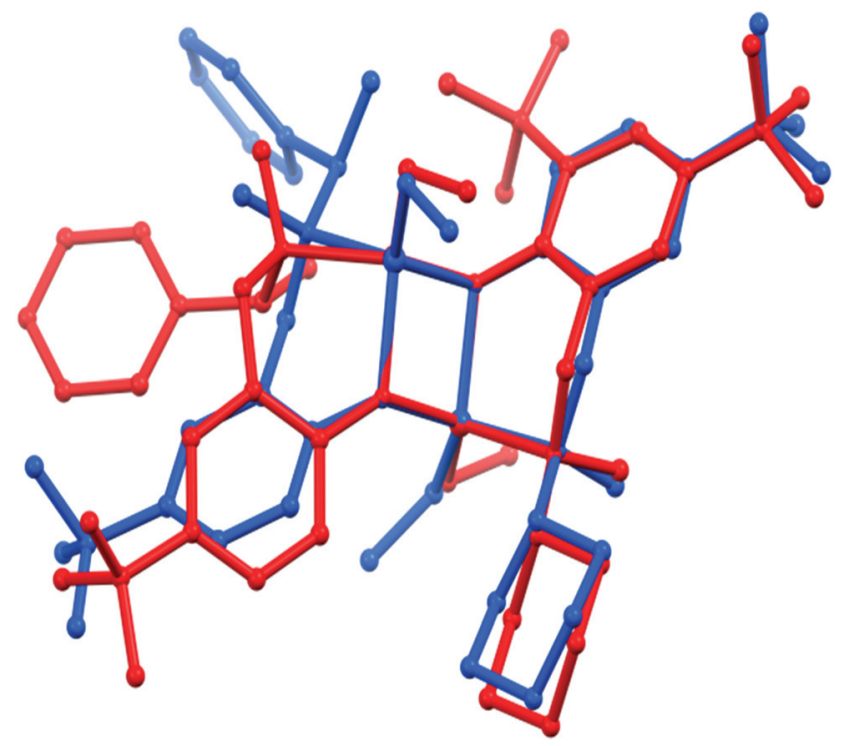

Fig. 14 Superimposed molecular structures of $\left(\mathrm{L}^{R} \mathrm{~L}^{\mathrm{cy}} \mathrm{Zn}_{2} \mathrm{Et}_{2}\right)$ (red) and $\left(\mathrm{L}^{R} \mathrm{~L}^{\mathrm{cy}} \mathrm{Zn}_{2} \mathrm{Et}_{2}\right)^{44}$ (blue). $\mathrm{H}$ atoms are omitted for the sake of clarity. 
Table 3 Selected bond distances $(\AA)$ and angles $\left(^{\circ}\right)$ for molecular structures of $\left(\mathrm{L}^{R} \mathrm{~L}^{\mathrm{cy}} \mathrm{ZnEt}\right)_{2}$ and $\left(\mathrm{L}^{R} \mathrm{七}^{\mathrm{cy}} \mathrm{ZnEt}\right)_{2}$

\begin{tabular}{|c|c|c|}
\hline Atoms & $\mathbf{L}^{R} \mathbf{L}^{\mathrm{cy}} \mathbf{Z n}_{2} \mathbf{E t}_{2}{ }^{a}$ & $\mathbf{L}^{R} \mathbf{L}^{\mathrm{cy}} \mathbf{Z n}_{2} \mathbf{E t}_{2}$ \\
\hline \multicolumn{3}{|c|}{ Bond distance $[\AA]$} \\
\hline Zn1-C21 & $1.990(6)$ & $1.977(6)$ \\
\hline $\mathrm{Zn} 2-\mathrm{C} 53^{b}$ & $2.002(6)$ & $1.993(7)$ \\
\hline Zn1-O1 & $2.033(3)$ & $2.017(4)$ \\
\hline $\mathrm{Zn} 2-\mathrm{O} 2$ & $2.029(3)$ & $2.044(4)$ \\
\hline $\mathrm{Zn} 1-\mathrm{O} 2$ & $2.046(4)$ & $2.025(4)$ \\
\hline $\mathrm{Zn} 2-\mathrm{O} 1$ & $2.038(4)$ & $2.055(4)$ \\
\hline Zn1-N1 & $2.164(4)$ & $2.194(5)$ \\
\hline $\mathrm{Zn} 2-\mathrm{N} 2$ & $2.151(4)$ & $2.147(5)$ \\
\hline $\mathrm{Zn} 1-\mathrm{Zn} 2^{c}$ & $3.0581(12)$ & $3.0592(10)$ \\
\hline $\mathrm{O} 1-\mathrm{O} 2^{c}$ & $2.690(4)$ & $2.683(4)$ \\
\hline \multicolumn{3}{|l|}{ Angels [] } \\
\hline C21-Zn1-O1 & $126.3(2)$ & $132.9(2)$ \\
\hline $\mathrm{C} 53^{b}-\mathrm{Zn} 2-\mathrm{O} 2$ & $125.57(19)$ & $119.8(2)$ \\
\hline C21-Zn1-O2 & $126.04(18)$ & $122.4(2)$ \\
\hline $\mathrm{C} 53^{b}-\mathrm{Zn} 2-\mathrm{O} 1$ & $120.43(19)$ & $129.3(2)$ \\
\hline O1-Zn1-O2 & $82.52(14)$ & $83.18(17)$ \\
\hline $\mathrm{O} 1-\mathrm{Zn} 2-\mathrm{O} 2$ & $82.83(14)$ & $81.79(17)$ \\
\hline C21-Zn1-N1 & $122.23(18)$ & $110.4(2)$ \\
\hline $\mathrm{C} 53^{b}-\mathrm{Zn} 2-\mathrm{N} 2$ & $123.2(2)$ & $121.6(2)$ \\
\hline O1-Zn1-N1 & $94.04(14)$ & $87.62(15)$ \\
\hline $\mathrm{O} 2-\mathrm{Zn} 2-\mathrm{N} 2$ & $93.27(14)$ & $94.26(14)$ \\
\hline $\mathrm{O} 2-\mathrm{Zn} 1-\mathrm{N} 1$ & $95.02(14)$ & $114.76(15)$ \\
\hline $\mathrm{O} 1-\mathrm{Zn} 2-\mathrm{N} 2$ & $102.08(15)$ & $99.28(15)$ \\
\hline $\mathrm{Zn} 1-\mathrm{O} 1-\mathrm{Zn} 2$ & $97.37(13)$ & $97.40(13)$ \\
\hline $\mathrm{Zn} 1-\mathrm{O} 2-\mathrm{Zn} 2$ & $97.24(14)$ & $97.50(13)$ \\
\hline
\end{tabular}

${ }^{a}$ Previously published. ${ }^{4{ }^{b}} \mathrm{C} 53=\mathrm{C} 49$ for $\mathbf{L}^{\boldsymbol{R}} \mathbf{L}^{\mathrm{cy}} \mathbf{Z n}_{2} \mathbf{E t}_{2} .{ }^{c}$ Values in parentheses refer to the non-bonding interactions.

benzyl substituent located at the nitrogen atom (Fig. 14, Table 3). This behavior may be the reason for the instability in the solution of the heterodimeric zinc complex $\left(\mathbf{L}^{R} \mathbf{L}^{\mathbf{c y}} \mathbf{Z n}_{\mathbf{2}} \mathbf{E} \mathbf{t}_{\mathbf{2}}\right)$.

\section{Conclusions}

A successful, based on DFT calculations, synthetic strategy has been developed for the synthesis of different aminophenolate zinc complexes. We have presented here a new heteroleptic $\left(\mathbf{L}^{\mathbf{o x}} \mathbf{Z n E t}\right)_{2}$ complex, which showed low catalytic activity in the ROP of lactides due to the stable dimeric structure and flexibility of an oxolane arm efficiently shielding the active metal centre during alcoholysis. The research showed that a greater steric hindrance of the aminophenolate ligand located on the aryloxo fragment results in homoleptic $\left(\mathbf{L}^{\mathbf{o x}}\right)_{2} \mathbf{Z n}$ complex formation, which was determined in the solid state as the most stable species among the numerously possible homo- and heteroleptic isomers. The theoretical studies, which were verified by the experimental data, suggested that the lability of the dioxolane fragment is essential to ensure a suitable structure of an active centre for zinc. The subtle changes observed in the calculated structures of the complexes allowed for the rational selection of substituents of the designed ligands in order to improve the active ROP initiators. The detailed analysis of the DFT data has been the inspiration for the synthesis of two heterodimers, $\left(\mathbf{L}^{\boldsymbol{R}} \mathbf{L}^{\mathbf{o x}} \mathbf{Z \mathbf { n } _ { 2 }} \mathbf{E t _ { 2 }}\right)$ and $\left(\mathbf{L}^{\boldsymbol{R}_{\mathbf{L}}} \mathbf{L}^{\mathbf{c y}} \mathbf{Z n}_{\mathbf{2}} \mathbf{E t _ { 2 }}\right)$, which were impossible to obtain by a classical, planned synthetic way.
Additionally, the complex $\left(\mathbf{L}^{R} \mathbf{L}^{\mathbf{o x}} \mathbf{Z n}_{\mathbf{2}} \mathbf{E} \mathbf{t}_{\mathbf{2}}\right)$ works in ROP reactions as an initiator with one active metal centre. While, the complex ( $\mathbf{L}^{\boldsymbol{R}} \mathbf{L}^{\mathbf{c y}} \mathbf{Z n}_{\mathbf{2}} \mathbf{E} \mathbf{t}_{\mathbf{2}}$ ), proved the existence in the solution of the monomeric species $\mathrm{E}^{\mathrm{cy}} \mathrm{ZnEt}$, which is difficult to isolate or even detect during the reaction between $\mathrm{七}^{\mathrm{cy}}$ and $\mathrm{ZnEt}_{2}$.

The presented here examples of new zinc complexes indicated that theoretical DFT calculations can be a valuable synthetic toolbox to tailor new complexes that are interesting for coordination chemistry. Additionally, the simple DFT assisted approach constitutes a valuable method for the qualification of an ancillary ligand for the design of new complexes not only as potential initiators for the ROP of lactides. Research showed that the free ortho-position of the aminophenol ligand $\mathrm{L}^{\mathrm{ox}}$ is one step too far because the aminophenolate zinc complex is inactive in the ROP reactions. Instead, the use of an appropriate ligand, including "exotic one", for example zinc containing moieties introduced via the "zebra reaction", is crucial for the improved catalytic activity.

The presented synthetic scenario is not dedicated to zinc complexes exclusively but is useful for the synthesis of other M(II) complexes with an appropriate coordination fitting code. The new examples of heterometal complexes constitute a subject of our intensive research at the moment, and the findings of this research will be soon published in another paper.

\section{Acknowledgements}

The author gratefully acknowledges the National Science Centre in Poland (Grant NN 204 200640), KNOW (under the project for Wrocław Biotechnology Center) and the Wrocław Centre for Networking and Supercomputing (http://www.wcss. wroc.pl).

\section{Notes and references}

1 R. Langer and D. A. Tirrell, Nature, 2004, 428, 487.

2 Z. Wang, H. Hu, Y. Wang, Q. Wu, L. Liu and G. Chen, Biomaterials, 2006, 27, 2550.

3 H. Sun, F. Meng, A. A. Dias, M. Hendriks, J. Feijen and Z. Zhong, Biomacromolecules, 2011, 12, 1937.

4 M. P. Arrieta, M. M. Castro-Lopez, E. Rayon, L. F. BarralLosada, J. M. Lopez-Vilarino, J. Lopez and M. V. GonzalezRodriguez, J. Agric. Food Chem., 2014, 62, 10170.

5 H. K. Lau and K. L. Kiick, Biomacromolecules, 2015, 16, 28.

6 M. Murariu, A. Doumbia, L. Bonnaud, A. L. Dechief, Y. Paint, M. Ferreira, C. Campagne, E. Devaux and P. Dubois, Biomacromolecules, 2011, 12, 1762.

7 H. Kim, H. Park, J. Lee, T. H. Kim, E. S. Lee, K. T. Oh, K. C. Lee and Y. S. Youn, Biomaterials, 2011, 32, 1685.

8 P. Zhang, H. Wu, Z. Lu, C. Deng, Z. Hong, X. Jing and X. Chen, Biomacromolecules, 2011, 12, 2667.

9 A. Bertrand and M. A. Hillmyer, J. Am. Chem. Soc., 2013, 135, 10918. 
10 M. Dusselier, P. Van Wouwe, A. Dewaele, P. A. Jacobs and B. F. Sels, Science, 2015, 349, 78.

11 B. J. O'Keefe, M. A. Hillmyer and W. B. Tolman, J. Chem. Soc., Dalton Trans., 2001, 2215.

12 J. Wu, T.-L. Yu, C.-T. Chen and C.-C. Lin, Coord. Chem. Rev., 2006, 250, 602.

13 R. H. Platel, L. M. Hodgson and C. K. Williams, Polym. Rev., 2008, 48, 11.

14 C. A. Wheaton, P. G. Hayes and B. J. Irealand, Dalton Trans., 2009, 25, 4832.

15 N. Ajellal, J. F. Carpentier, C. Guillaume, S. M. Guillaume, M. Helou, V. Poirier, Y. Sarazin and A. Trifonov, Dalton Trans., 2010, 39, 8363.

16 S. Dagorne, M. Normand, E. Kirillov and J.-F. Carpentier, Coord. Chem. Rev., 2013, 257, 1869.

17 S. Dagorne and C. Fliedel, Top. Organomet. Chem., 2013, 41, 125.

18 A. Sauer, A. Kapelski, C. Fliedel, S. Dagorne, M. Kol and J. Okuda, Dalton Trans., 2013, 42, 9007.

19 S. Dagorne, F. Le Bideau, R. Welter, S. Bellemin-Laponnaz and A. Maisse-François, Chem. - Eur. J., 2007, 13, 3202.

20 M. Cheng, A. B. Attygalle, E. B. Lobkovsky and G. W. Coates, J. Am. Chem. Soc., 1999, 121, 11583.

21 B. M. Chamberlain, M. Cheng, D. R. Moore, T. M. Ovitt, E. B. Lobkovsky and G. W. Coates, J. Am. Chem. Soc., 2001, 123, 3229.

22 M. H. Chisholm, J. Gallucci and K. Phomphrai, Inorg. Chem., 2002, 41, 2785.

23 M. H. Chisholm and K. Phomphrai, Inorg. Chim. Acta, 2003, 350, 121.

24 A. P. Dove, V. C. Gibson, E. L. Marshall, A. J. P. White and D. J. Wiliams, Dalton Trans., 2004, 570.

25 R. Han and G. Parkin, J. Am. Chem. Soc., 1992, 114, 748.

26 M. H. Chisholm and N. W. Eilerts, Chem. Commun., 1996, 853.

27 M. H. Chisholm, N. W. Eilerts, J. C. Huffman, S. S. Iyer, M. Pacold and K. Phomphrai, J. Am. Chem. Soc., 2000, 122, 11845.

28 M. H. Chisholm, J. Gallucci and K. Phomphrai, Inorg. Chem., 2004, 43, 6717.

29 C. K. Williams, L. E. Breyfogle, S. K. Choi, W. Nam, V. G. Young Jr., M. A. Hillmyer and W. B. Tolman, J. Am. Chem. Soc., 2003, 125, 11350.

30 J. Ejfler, M. Kobyłka, L. B. Jerzykiewicz and P. Sobota, Dalton Trans., 2005, 2047.

31 H. Y. Chen, H. Y. Tang and C. C. Lin, Macromolecules, 2006, 39, 3745.

32 Z. Zheng, G. Zhao, R. Fablet, M. Bouyahyi, C. M. Thomas, T. Roisnel, O. Casagrande Jr. and J. F. Carpentier, New J. Chem., 2008, 32, 2279.

33 J. Ejfler, S. Szafert, K. Mierzwicki, L. B. Jerzykiewicz and P. Sobota, Dalton Trans., 2008, 6556.

34 G. Labourdette, D. J. Lee, B. O. Patrick, M. B. Ezhova and P. Mehrkhodavandi, Organometallics, 2009, 28, 1309.
35 J. Ejfler, K. Krauzy-Dziedzic, S. Szafert, L. B. Jerzykiewicz and P. Sobota, Eur. J. Inorg. Chem., 2010, 3602.

36 V. Poirier, T. Roisnel, J.-F. Carpentier and J. Sarazin, Dalton Trans., 2011, 40, 523.

37 H.-J. Chuang, S.-F. Weng, C.-C. Chang, C.-C. Lin and H.-Y. Chen, Dalton Trans., 2011, 40, 9601.

38 N. Ikpo, L. N. Saunders, J. L. Walsh, J. M. B. Smith, L. N. Dawe and F. M. Kerton, Eur. J. Inorg. Chem., 2011, 35, 5347.

39 A. Grala, J. Ejfler, L. B. Jerzykiewicz and P. Sobota, Dalton Trans., 2011, 40, 4042.

40 S. Song, X. Zhang, H. Ma and Y. Yang, Dalton Trans., 2012, 41, 3266.

41 J. Wojtaszak, K. Mierzwicki, S. Szafert, N. Gulia and J. Ejfler, Dalton Trans., 2014, 43, 2424.

42 D. Jędrzkiewicz, I. Czeluśniak, M. Wierzejewska, S. Szafert and J. Ejfler, J. Mol. Catal. A: Chem., 2015, 196, 155.

43 D. Jędrzkiewicz, J. Ejfler, N. Gulia, Ł. John and S. Szafert, Dalton Trans., 2015, 44, 13700.

44 D. Jędrzkiewicz, J. Ejfler, Ł. John and S. Szafert, Dalton Trans., 2016, 45, 2829.

45 D. Jędrzkiewicz, G. Adamus, M. Kwiecień, Ł. John and J. Ejfler, Inorg. Chem., 2017, 56, 1349.

46 CrysAlisRED Software, Oxford Diffraction, Wrocław, Poland, 1995-2004.

47 G. M. Sheldrick, Acta Crystallogr., Sect. A: Fundam. Crystallogr., 2008, 64, 112.

48 C. F. Macrae, I. J. Bruna, J. A. Chisholm, P. R. Edgington, P. Mccabe, E. Pidcock, L. Rodriguez-Monge, R. Taylor, J. van de Streek and P. A. Wood, J. Appl. Crystallogr., 2008, 41, 466.

49 M. J. Frisch, G. W. Trucks, H. B. Schlegel, G. E. Scuseria, M. A. Robb, J. R. Cheeseman, G. Scalmani, V. Barone, B. Mennucci, G. A. Petersson, H. Nakatsuji, M. Caricato, X. Li, H. P. Hratchian, A. F. Izmaylov, J. Bloino, G. Zheng, J. L. Sonnenberg, M. Hada, M. Ehara, K. Toyota, R. Fukuda, J. Hasegawa, M. Ishida, T. Nakajima, Y. Honda, O. Kitao, H. Nakai, T. Vreven, J. A. Montgomery, Jr., J. E. Peralta, F. Ogliaro, M. Bearpark, J. J. Heyd, E. Brothers, K. N. Kudin, V. N. Staroverov, T. Keith, R. Kobayashi, J. Normand, K. Raghavachari, A. Rendell, J. C. Burant, S. S. Iyengar, J. Tomasi, M. Cossi, N. Rega, J. M. Millam, M. Klene, J. E. Knox, J. B. Cross, V. Bakken, C. Adamo, J. Jaramillo, R. Gomperts, R. E. Stratmann, O. Yazyev, A. J. Austin, R. Cammi, C. Pomelli, J. W. Ochterski, R. L. Martin, K. Morokuma, V. G. Zakrzewski, G. A. Voth, P. Salvador, J. J. Dannenberg, S. Dapprich, A. D. Daniels, O. Farkas, J. B. Foresman, J. V. Ortiz, J. Cioslowski and D. J. Fox, Gaussian 09, Revision B.01, Gaussian, Inc., Wallingford CT, 2010.

50 A. D. Becke, J. Chem. Phys., 1993, 98, 5648.

51 C. Lee, W. Yang and R. G. Parr, Phys. Rev. B: Condens. Matter, 1988, 37, 785.

52 A. Kowalski, A. Duda and S. Penczek, Macromolecules, 1998, 31, 2114. 